\title{
Diferenciação regional da indústria brasileira agrupamento e ordenação a partir de um novo índice
}

\author{
João Saboia \\ Professor do Instituto de Economia da UFRJ \\ Lucia Kubrusly \\ Professora do Instituto de Economia da UFRJ \\ Amir Coelho Barros \\ Pesquisador do Instituto de Economia da UFRJ
}

\section{Palauras-chave}

indústria brasileira, indústria regional, indicadores

econômicos.

Classificação JEL C43; L60; R12.

Key words

Brazilian industry, regional industry, economic indicators.

JEL Classification C43; L60, R12.

\section{Resumo}

A partir da análise de componentes principais, é proposto um indicador para estimar o nível de desenvolvimento da indústria nas unidades da federação e nas 137 mesorregiões do país. Os resultados encontrados confirmam os desequilíbrios regionais existentes destacando os estados das regiões Sul e Sudeste com resultados mais favoráveis. A análise por mesorregião confirma a melhor situação dos estados do Sul/Sudeste, indicando, porém, a existência de alto grau de heterogeneidade em seu interior. Foram ainda encontrados dados relativamente favoráveis em algumas mesorregiões do Norte, Nordeste e CentroOeste. Em alguns casos, trata-se de regiões metropolitanas ao redor das capitais. Em outros, resulta de políticas explícitas de atração de investimentos industriais. Foi também desenvolvida uma análise de agrupamento, procurando encontrar estados e mesorregiões com dados industriais semelhantes. Conforme esperado, o estado de São Paulo e a Região Metropolitana de São Paulo são os dois destaques em termos de unidades da federação e de mesorregiões, a ponto de serem considerados grupos individuais bem distintos dos demais. Vários outros grupos e subgrupos são formados com níveis de desenvolvimento industrial claramente diferenciados. A comparação entre os indicadores estimados e os grupos formados mostra uma nítida associação entre os resultados obtidos com os dois métodos de análise utilizados no trabalho.

\begin{abstract}
This article proposes a new indicator based on principal component analysis to study the level of development of Brazilian industry. Its utilization on regional data shows high disequilibrium among different regions. Results are much more favorable in the South and Southeast than in the rest of the country. This is true when comparing the 27 states as well as the 137 mesoregions. A high degree of heterogeneity in the interior of the most developed states was also identified. There are a few cases of success in the North, Northeast end Center-West regions; in some cases, these are metropolitan regions surrounding the state capitals; in others they are related to specific local policies to attract new investments. In the second part of the paper cluster analysis is used to show the similarities among the regions. The state of São Paulo and its metropolitan region are two outliers showing the best results in the country. Various groups with different level of development are formed. The comparison between the results encountered in both analysis (cluster and principal components) shows a strong association. As expected, regions with similar values for the indicator tend to belong to the same group.
\end{abstract}




\section{1_Introdução}

Os estudos sobre a localização da indústria brasileira ganharam forte impulso a partir da década de 1990. Inicialmente, esses trabalhos apresentavam enfoque predominantemente histórico sobre as condições do desenvolvimento econômico brasileiro. Isso pode ser visto, por exemplo, em Cano (1977 e 1985). Em termos gerais, a industrialização brasileira seguiu a dinâmica tradicional de concentração das atividades fabris e o aproveitamento de economias de escala e aglomeração. A cidade de São Paulo tornou-se o centro polarizador primaz desse processo, atingindo seu ápice em 1970, quando era responsável por quase metade da produção industrial do País conforme Lemos et al. (2005).

Embora as primeiras construções institucionais (Sudene, BNB, Sudam) que tratam da geopolítica da integração nacional remontem ainda aos anos 60 , é na década de 1970 que o Estado brasileiro desempenhará papel decisivo na busca da integração econômica do território nacional. Um conjunto de ações governamentais (II PND) vai privilegiar investimentos em regiões até então não desenvolvidas. Como destaca Diniz e Crocco (1996), esse é um dos principais fatores que impulsionaram o processo de desconcentração econômica e que envolveriam: a. deseconomias de aglomeração na área metropolitana de São Paulo e criação de economias de aglomeração em vários outros centros urbanos e regiões;

b. ação do Estado em termos de investimento direto, incentivos fiscais e construção de infra-estrutura;

c. busca de recursos naturais com a expansão da fronteira agrícola e mineral;

d. unificação do mercado potencializada pelo desenvolvimento da infra-estrutura de transportes e comunicações;

e. efeitos locacionais da competição interempresarial com ocupação de novos mercados reais ou potenciais.

A discussão da natureza e extensão desse processo de desconcentração tem como ponto de partida os trabalhos de Diniz (1993) e Diniz e Crocco (1996). Esses estudos apontam para um movimento de desconcentração industrial ocorrido entre 1970 e 1991. No centro desse processo, estão as perdas significativas na participação das Regiões Metropolitanas de São Paulo e Rio de Janeiro tanto em termos do emprego quanto no valor da transformação industrial. Essas perdas teriam como contra- 
partida um aumento na participação do próprio interior do Estado de São Paulo, dos Estados do Sul e de Minas Gerais. Um novo "mapa" da atividade industrial configuraria um "polígono" partindo do centro de Minas Gerais até o nordeste do Rio Grande do Sul. Para Diniz e Crocco (1996), as transformações ocorridas na década de 1990 (abertura comercial, financeira, desregulamentação...) fariam com que o processo de desconcentração ficasse limitado às cidades do polígono.

A partir desse momento, uma série de trabalhos vai discutir como essas transformações impactariam a localização espacial da indústria brasileira. Desta forma, Pacheco (1999) avança a análise para cobrir o período 1986-96, concluindo que o processo de desconcentração prosseguiu, ainda que de forma mais discreta. Contudo, chama a atenção para o fato de que as mudanças nos padrões locacionais não são uniformes, havendo padrões setoriais distintos.

Andrade e Serra (2000) analisam a desconcentração industrial tendo por base os municípios do próprio "polígono" sugerido por Diniz e Crocco (1996). Suas conclusões apontam para uma estagnação do processo, visto que a participação dos municípios do polígono no emprego industrial se manteve praticamente estável na primeira metade dos anos 90. No que se refere ao interior do polígono, há um processo de desconcentração espacial com redução da importância das áreas industriais tradicionais. Mais ainda é ressaltada a nãoexistência de um padrão nítido de distribuição espacial das taxas de variação do emprego industrial. Dessa maneira, os autores destacam a presença de áreas de "vazios industriais", de queda no nível de emprego industrial e ilhas de prosperidade dentro do próprio polígono.

Saboia (2000), utilizando dados da Rais (BRASIL, 2004) para o período 19891997, além de evidenciar um movimento de desconcentração presente nas grandes regiões e Estados, indica um declínio do emprego industrial nas capitais e nas regiões metropolitanas em prol do fortalecimento do interior dos principais Estados industrializados e de alguns fora do eixo Sul-Sudeste. Ainda mais, estariam surgindo pequenas aglomerações industriais nas mais distintas regiões do País. Esses espaços se caracterizam por apresentarem baixos salários (menor nível de escolaridade) e pequeno nível de diversificação industrial.

Azevedo e Toneto Júnior (2001) apontam para a continuação do processo de desconcentração na década de 1990. No entanto, aprofundam uma discussão sobre os movimentos setoriais por trás desse processo. Assim, os setores intensivos em tra- 
balho migrariam para regiões com salários mais baixos (como Nordeste). Já os setores intensivos em recursos naturais deslocaram-se para onde o recurso está disponível (como Centro-Oeste). As indústrias intensivas em capital sofreram realocações próximas a São Paulo (Paraná e Minas Gerais).

Saboia (2001) confirma os fortes movimentos de relocalização espacial ocorridos na década de 1990, mostrando que a região Sul foi a principal beneficiária das mudanças, com crescimento relativo de sua participação no emprego e nos salários dos mais diversos setores industriais. Destaca também o crescimento da importância das regiões Nordeste e Centro-Oeste em vários segmentos da indústria tradicional.

O trabalho de Suzigan et al. (2001) discute a questão da descentralização industrial tendo por base o Estado de São Paulo. Os resultados indicam um desempenho melhor das microrregiões no interior do Estado diante da região metropolitana. Mesmo assim, o trabalho destaca a ampla heterogeneidade entre essas aglomerações industriais.

Saboia (2004) retoma a questão da desconcentração espacial da indústria no período 1994-2000, para analisar se esse processo teria beneficiado a região Nordeste. Apoiado em indicadores sintéticos (inspirados no IDH), o artigo analisa, pri- meiramente, o comportamento da indústria nordestina, vis-à-vis às demais regiões do País. Posteriormente, a mesma metodologia é aplicada aos Estados do Nordeste. Ainda que essa região apresente melhora em alguns aspectos da sua indústria (no nível de emprego, na remuneração média, no número de estabelecimentos, por exemplo), Saboia ressalta as enormes diferenças existentes entre os Estados da região. Essas diferenças sugerem que se faça uma análise da indústria nordestina num nível espacial mais desagregado.

A discussão proposta por Ramos e Ferreira (2005) traz para o debate a questão do comportamento diferenciado entre "um Brasil metropolitano" versus um "não metropolitano". Valendo-se de um indicador que avalia a realocação dos empregos industriais (índice de turbulência), a descentralização da indústria se dá tanto pelo esgotamento das metrópoles como pólos industriais quanto como resultante do processo de guerra fiscal entre Estados. A perda de importância relativa do eixo Rio-São Paulo, principalmente da região metropolitana deste último Estado, implicou a "migração" de postos de trabalho industriais para o interior do próprio Estado e para Estados vizinhos (com exceção do Rio de Janeiro, cuja região metropolitana apresentou a segunda maior perda no emprego industrial). $\mathrm{O}$ ar- 
tigo ressalta ainda que as disparidades na distribuição do emprego industrial são bem maiores que as encontradas para a ocupação total do País.

Sob um enfoque econômico-demográfico, pode ainda ser mencionado o estudo de Garcia, Lemos e Carvalho (2003) mostrando as importantes mudanças ocorridas nos pólos econômicos do País no período 1980/2000, especialmente ao longo da década de 1990.

Os trabalhos de Pereira e Lemos (2003), Lemos et al. (2003) focalizam o desenvolvimento das cidades brasileiras, buscando uma compreensão das dinâmicas urbano-industriais subjacentes. $\mathrm{O}$ ponto de destaque aqui é para a visão de que

a distribuição espacial da indústria brasileira é concentrada pela força hegemônica de São Paulo e seu entorno regional, mas existem pólos subnacionais que são forças efetivas de atração de investimentos industriais e centros irradiadores da industrialização para suas áreas de influência geográfica (Lemos et al., 2003, citado em Lemos et al., 2005).

Uma característica presente nos trabalhos sobre a questão da localização espacial da indústria brasileira é, sem dúvida, a presença de uma extrema heterogeneidade dessa distribuição. Como destacado em Suzigan et al. (2001), Andrade e Serra (2000) e
Saboia (2000, 2001 e 2004), essa heterogeneidade está presente em todos os níveis de recorte espacial. E não se trata aqui apenas da questão do emprego industrial em si, mas das várias características que formam determinada estrutura industrial.

Focalizando a questão regional da indústria no Brasil, este artigo desenvolve um estudo sobre os diferenciais regionais no nível de desenvolvimento da indústria de transformação e extrativa mineral, mediante uma visão multidimensional das estruturas industriais que dê conta da heterogeneidade espacial dessas estruturas.

Em geral, os resultados encontrados são aqueles esperados a priori. Há, entretanto, algumas novidades tanto na análise por Unidade da Federação (UF) quanto, principalmente, por mesorregiões.

No caso da análise estadual, talvez a principal surpresa seja o resultado bastante favorável encontrado no Estado do Amazonas, comparável aos obtidos nas demais Unidades da Federação das regiões Sul e Sudeste, inferior apenas aos de São Paulo e Rio de Janeiro.

$\mathrm{Na}$ análise mesorregional, é obtido um resultado que não tem tido grande destaque na literatura sobre economia regional, que costuma tratar os Estados de forma homogênea. Verifica-se a existência de maior nível de heterogeneidade no interior 
dos Estados mais desenvolvidos do que nos demais. Em outras palavras, haveria dentro dos Estados mais desenvolvidos grande dispersão em termos de desenvolvimento industrial, ao mesmo tempo em que a situação nos Estados menos desenvolvidos é de maior homogeneidade.

Na próxima seção, é apresentada a metodologia utilizada no artigo. Em seguida, são apresentados os resultados da análise por Unidade da Federação (seção 3) e mesorregião (seção 4). O trabalho é encerrado com as principais conclusões. Há ainda um anexo com dados selecionados das mesorregiões.

\section{2_Metodologia}

A metodologia elaborada para este trabalho está baseada em técnicas estatísticas multivariadas, mais especificamente Análise de Componentes Principais (ACP) e Análise de Grupamento (AG). É proposto um índice de "desenvolvimento industrial" elaborado com base na primeira componente da ACP, que permite ordenar as regiões consideradas, diferenciando seu nível de desenvolvimento. Em seguida, buscam-se grupos de regiões "semelhantes" utilizando Análise de Grupamento.

\section{1_ A base de dados}

A fonte de dados utilizada neste trabalho é a Relação Anual de Informações Sociais
(Rais) para o ano de 2004' . Embora a Rais inclua apenas o setor formal da economia brasileira, no caso específico da indústria de transformação e extrativa mineral, essa não constitui maior óbice quanto à representatividade, visto que seu grau de formalização é bastante alto. Além disso, a cobertura da Rais é relativamente homogênea nas diversas regiões do País, mesmo quando se trabalha com níveis espaciais mais desagregados.

Em geral, essas variáveis estão disponibilizadas diretamente pela Rais, representando a situação em 31/12/2004. Duas observações, entretanto, são necessárias. A escolaridade não é informada em anos de estudo, sendo necessárias algumas hipóteses sobre sua distribuição no interior das faixas informadas. Por outro lado, há necessidade de se definir o que se entende por profissionais técnicos e científicos. ${ }^{2}$

\section{2_A escolha das variáveis}

A caracterização da indústria foi baseada em dois principais aspectos. $\mathrm{O}$ primeiro diz respeito à "organização interna" do processo produtivo e envolve não somente atributos da mão-de-obra como também a própria complexidade da estrutura industrial. Essa caracterização tem por base:

\footnotetext{
Quando os dados

do artigo foram processados, 2004 era o ano mais recente disponibilizado pela Rais (BRASIL, 2004).

2 Para os profissionais técnicos e científicos, foram considerados os grandes grupos 2 e 3 da nova CBO 2002. Para transformar as faixas de escolaridade em anos de estudo, foram utilizados os seguintes valores médios para cada faixa: analfabeto $=0$; $4^{\mathrm{a}}$ série incompleta $=2$; $4^{\mathrm{a}}$ série completa $=4$; $8^{\mathrm{a}}$ série incompleta $=6$; $8^{\mathrm{a}}$ série completa $=8$; $2^{\circ}$ grau incompleto $=9,5$; $2^{\circ}$ grau completo $=11 ;$ superior incompleto $=13$; superior completo $=15,5$.
} 
a. remuneração média mensal da mão-deobra empregada - o nível de remuneração de uma indústria, além de informar sobre a qualidade do emprego, indica o nível de sofisticação tecnológica das empresas: "As empresas que inovam e diferenciam seus produtos pagam, em média, maiores salários..." (De Negri e Salerno, 2005). Por outro lado, a remuneração está intimamente ligada ao nível de produtividade do trabalhador.

b. escolaridade média do pessoal ocupadoo nível de educação formal também é uma proxy para o nível tecnológico da firma: “É razoável supor que firmas com maior conteúdo tecnológico demandem mão-de-obra mais qualificada” (De Negri e Salerno, 2005).

c. percentual de trabalhadores relacionados às atividades técnico-científicas - essa característica, além de expressar a intensidade do trabalho mais qualificado, revela a capacidade potencial que uma indústria tem em realizar inovações, diferenciar seus produtos, melhorar sua eficiência técnica de forma geral; enfim, uma indústria com maior complexidade tecnológica.
O segundo critério trata da capacidade da indústria em dinamizar as atividades econômicas na sua região:

d. número de empregados - além da relação com o impacto no mercado de trabalho local, o número de empregados na indústria de uma região poder ser usado como uma proxy para o volume da produção industrial.

e. número de estabelecimentos - a utilização desse indicador (junto com o número de empregados) tem por finalidade avaliar a densidade da estrutura industrial de determinada região.

Em suma, o conceito de desenvolvimento industrial, conforme utilizado neste artigo, trabalha com a hipótese de que as regiões com estruturas industriais mais desenvolvidas apresentam maior número de estabelecimentos, empregam mais pessoas, pagam melhores salários e utilizam trabalhadores mais escolarizados com maior incidência de profissionais técnicos e científicos.

De certa forma, está sendo suposto implicitamente que o desenvolvimento industrial está associado ao maior nível de produtividade da indústria local, que, por sua vez, está associado positivamente com o nível de remuneração dos trabalhadores. Como veremos adiante, as cinco variáveis 
utilizadas estão associadas positivamente. Embora não esteja sendo empregada nenhuma variável de "resultados" da indústria, trabalhos anteriores apóiam, de certa forma, a metodologia aqui utilizada. ${ }^{3}$ Por outro lado, está sendo suposto que os centros mais desenvolvidos caracterizam-se por concentrarem maior número de estabelecimentos e de empregados.

\section{3_Sobre a utilização das mesorregióes}

Essa escolha do nível mesorregião segue um termo de compromisso entre a capacidade de evidenciar aspectos fundamentais das estruturas industriais (não perceptíveis nos níveis grandes regiões e Unidades da Federação) e a operacionalidade do processo de análise. Desta forma, as 137 mesorregiões representam classificação regional intermediária entre as 27 UFs e as 556 microrregiões, viabilizando sua discussão dentro do tamanho razoável para um artigo.

\section{4_A elaboração do Índice de Desenvolvimento Industrial}

Baseando-se na definição das cinco variáveis que expressam nosso conceito de "desenvolvimento industrial", o processo de análise volta-se para a construção de um indicador que permita a ordenação das regiões tendo por base o seu "desempenho global" nessas variáveis. Para isso, podemos calcular uma média ponderada das variáveis para cada região e, assim, obter um índice de desempenho que possibilitaria ordenar as unidades espaciais.

$\mathrm{Na}$ construção de índices, muitos métodos são utilizados para ponderar as variáveis. O objetivo de cada construção é obter pesos que traduzam a importância das variáveis. Numa abordagem estatística, uma medida muito usada é a variância. De certa forma, a variância traduz a informação contida numa variável. Ao construirmos um índice como uma combinação linear das variáveis, é desejável que esse contenha a maior variância possível, ou seja, que contenha o máximo de informação fornecida pelo conjunto de variáveis. A Análise de Componentes Principais (ACP) é um método que possibilita criarmos combinações lineares com essa propriedade (máxima variância). ${ }^{4}$

Segue-se a apresentação do índice proposto.

Seja um conjunto de $n$ objetos $O_{1}, \ldots, O_{n}$ que se deseja ordenar, segundo um conjunto de $p$ variáveis $X_{1}, \ldots, X_{p}$. A cada objeto $O_{i}$, associamos um valor $I_{i}=p_{1} X_{i 1}+p_{2} X_{i 2}+\ldots+p_{p} X_{i p}$ onde: $X_{i 1}, X_{i 2}, \ldots, X_{i p}$ são os valores das variáveis observadas para $O_{i}$; $p_{1}, p_{2}, \ldots, p_{p}$ são os pesos das variáveis.

\footnotetext{
3 Ver, por exemplo, Andrade e Serra (2000), Kupfer e Rocha (2004), Sabóia e Kubrusly (2008).

4 Uma abordagem mais detalhada para a construção de índices pode ser vista em Kubrusly (2001), e um estudo completo do modelo de Análise de Componentes Principais pode ser encontrado em Johnson e Wichern (1992).
} 
5 Um exemplo de aplicação desta técnica para construção de índices pode ser vista em Kubrusly (2001).
Como afirmado acima, os pesos escolhidos devem traduzir a importância de cada variável, isto é, às variáveis mais importantes na ordenação devem ser atribuídos os maiores pesos. Assim podemos estabelecer a ligação entre importância e variância. Sendo a ACP uma técnica que fornece a primeira componente com variância máxima, usaremos essa componente $\left(C_{1}\right)$ como índice.

$I_{i}=a_{1} X_{i 1}+a_{2} X_{i 2}+\ldots+a_{p} X_{i p}$

onde: $i=1, \ldots, n$, referem-se aos objetos que serão ordenados.

Assim, os pesos de cada variável serão os coeficientes que definem a primeira componente principal.

A utilização da ACP na construção do índice garante que:

- pesos maiores estarão associados às variáveis que contribuem mais para a variância do conjunto dos dados;

- o índice resultante será padronizado: média zero, desvio padrão unitário.

Portanto, na leitura dos resultados, as regiões com desempenho "médio" receberão valores em torno de "0" para o índice, enquanto as melhores receberão os valores mais altos (positivos), e as piores receberão os valores mais baixos (negativos). ${ }^{5}$ Os índices são calculados de tal forma que per- mitem uma ordenação das regiões segundo os valores das cinco variáveis utilizadas - número de estabelecimentos, emprego, remuneração, escolaridade e percentual de trabalhadores técnicos e científicos.

O índice resultante é uma média ponderada das cinco variáveis. Quanto maior o valor do índice, maior tende a ser o número de estabelecimentos, a quantidade de emprego, o nível de remuneração e de escolaridade dos trabalhadores e o percentual de trabalhadores técnicos e científicos da respectiva indústria.

\section{5_Identificação de estruturas industriais semelhantes}

O objetivo nessa etapa é tentar identificar se existem regiões com estruturas espaciais semelhantes. A Análise de Grupamento (AG) é uma técnica que se ajusta a esse objetivo. Basicamente, a estrutura industrial de uma região é caracterizada pelas cinco variáveis descritas acima. Mais precisamente, cada região é representada por um vetor do $\mathbf{R}^{5}$. Cada método da AG define uma forma de medir a "distância" entre esses pontos e, dessa forma, estabelece uma medida de semelhança entre as regiões. Neste trabalho, será utilizado um método hierárquico, o método de Ward, com as cinco variáveis padronizadas (Barros, 1992; Johnson e Wichern, 1992). 


\section{3_Análise das Unidades da Federação}

Nesta seção, são apresentados os principais resultados empíricos encontrados nas Unidades da Federação (UFs).

\section{1_ Uma visão do comportamento das variáveis}

Inicialmente, será apresentada uma breve análise descritiva das cinco variáveis utilizadas no trabalho para as 27 UFs.

\subsection{1_ Número de empregos industriais}

São Paulo é o grande destaque quando observamos a distribuição espacial do emprego industrial. Com seus $2.078 .525 \mathrm{em}$ pregos, concentrava 34,9\% da mão-de-obra industrial do País em 2004. Mais de três vezes o volume do emprego em Minas Gerais (629.321) e Rio Grande do Sul (620.639), que lhe seguem. No outro extremo, temos Roraima (1.523), Amapá (2.779) e Acre (3.644) com participação ínfima no emprego industrial do País.

Apenas dez Estados possuem mais de 100.000 empregos industriais. Além de São Paulo, Minas Gerais e Rio Grande do Sul, já citados, podem ser mencionados, por exemplo, Santa Catarina (482.931), Paraná (482.259) e Bahia (148.102). A assimetria na distribuição fica evidente quando notamos que o número médio de empregos fica em torno dos 220 mil, enquanto a mediana registra apenas 86 mil.
Os Estados das regiões Sul e Sudeste possuíam juntos 4.714.917 empregos, totalizando 79,2\% do emprego industrial. Em relação aos Estados das outras regiões, podemos ainda destacar o Ceará (176.854), Pernambuco (147.209) e Goiás (135.717).

\subsection{2_ Número de estabelecimentos industriais}

A distribuição regional dos estabelecimentos industriais possui certa semelhança com a distribuição do emprego. Novamente, São Paulo aparece com destaque ao concentrar 29,4\% dos estabelecimentos industriais do País (79.854). Apenas seis Estados das regiões Sul e Sudeste (SP, MG, RS, SC, PR e RJ) possuem mais de 10.000 estabelecimentos industriais. Se acrescentarmos o Espírito Santo, totalizam 215.761 estabelecimentos industriais, representando $79,4 \%$ do total da indústria, praticamente o mesmo percentual do emprego nas duas regiões. Fora dessas regiões, destacam-se Goiás (8.641), Bahia (7.533), Ceará (6.871) e Pernambuco (6.547) (ver Tabela 1).

Tabela 1_Estatísticas Descritivas - Unidades da Federação

\begin{tabular}{|c|c|c|c|c|}
\hline Variáveis & Mínimo & Máximo & Média & Desvio padrão \\
\hline Remuneração (R\$) & 431 & 1.492 & 745 & 277 \\
\hline Escolaridade (anos) & 3,6 & 10,5 & 7,8 & 1,2 \\
\hline Técnicos $(\%)$ & 4 & 17,3 & 8 & 3,3 \\
\hline$\underline{\mathrm{N}^{\circ} \text { de empregados }}$ & 1.523 & 2.078 .525 & 220.577 & 416.123 \\
\hline $\mathrm{N}^{\circ}$ de estabelecimentos & 170. & 79.854 & 10.067 & 17.100 \\
\hline
\end{tabular}

Fonte: Processamento dos autores a partir dos dados da RAIS 2004. 


\subsubsection{Remuneração média mensal na indústria}

A primeira observação sobre a remuneração dos trabalhadores da indústria aponta para grandes desníveis regionais. Assim, em 2004, a remuneração média mensal variava entre $R \$ 431,00$ no Piauí e $\mathrm{R} \$ 1.492,00$ no Rio de Janeiro. A remuneração média na indústria brasileira era de $\mathrm{R} \$ 745,00$ enquanto o rendimento mediano era de $\mathrm{R} \$ 668,00$.

Apenas 3 Estados pagavam em média mais de R\$1.000,00 (3,8 SM): Rio de Janeiro, com R\$1.492,00; São Paulo, com R\$1.401,00; e Amazonas, com R \$1.142,00. Por outro lado, 17 Estados apresentavam remuneração média inferior a R \$ 800,00 (3,1 $\mathrm{SM}$ ), sendo que em oito desses a remuneração média não chegava a 2 SM ( $\$$ \$ 520,00).

Conforme esperado, considerando-se as grandes regiões, as maiores remunerações concentravam-se nos Estados das regiões Sul e Sudeste. Contudo, é importante notar a presença de Estados de outras regiões entre os que pagavam as melhores remunerações. Esse é o caso da Bahia $(\mathrm{R} \$ 985,00)$ e Sergipe (R\$ 849,00), na região Nordeste; do Distrito Federal ( $\mathrm{R} \$ 976,00)$, na região Centro-Oeste; e, principalmente, do Amazonas, na região Norte, com o terceiro maior valor, $\mathrm{R} \$ 1.142,00$.

Já as piores remunerações médias encontravam-se, predominantemente, nos Estados das regiões Norte e Nordeste. Des- ta forma, Rondônia ( $\mathrm{R} \$ 498,00)$, Paraíba ( $\mathrm{R} \$ 488,00)$, Acre e Tocantins ( $\mathrm{R} \$ 474,00)$, Roraima $(\mathrm{R} \$ 471,00)$ e o Piauí $(\mathrm{R} \$ 431,00)$ apresentavam valores que nem sequer chegavam a 2 SM.

\subsection{4_Escolaridade da mão-de-obra industrial}

O diferencial entre os níveis de escolaridade dos trabalhadores industriais em 2004 é menor que aquele verificado para a remuneração. Assim, o número médio de anos de estudo oscilava entre os 3,6 em Alagoas e 10,5 no Amazonas. A escolaridade média era de 7,8 anos (mesmo valor da mediana), sendo os valores mais freqüentes em torno de 7 anos de estudo.

Os melhores níveis educacionais localizavam-se no Amazonas (10,5 anos de estudo), em São Paulo e no Distrito Federal $(9,2)$ e no Rio de Janeiro $(9,0)$.

Todos os sete Estados das regiões Sul e Sudeste têm a média de sua força de trabalho com pelo menos o ensino fundamental (8 anos ou mais), ainda que, em nenhuma delas, se atinja o ensino médio completo (11 anos). Fora dessas regiões, merecem destaque, além do Amazonas e do Distrito Federal, já mencionados, a Bahia $(8,4)$, Goiás $(8,3)$ e o Ceará $(8,1)$.

Em compensação, em 15 Estados a escolaridade média dos trabalhadores não atinge nem o nível fundamental (8 anos). São Estados localizados nas regiões Norte, Nordeste e Centro-Oeste. 


\subsubsection{Participação dos trabalhadores técnicos} e científicos na mão-de-obra industrial

A participação de trabalhadores das profissões técnicas e científicas é relativamente baixa na indústria brasileira. Em 2004, essa variava de $4 \%$ em Alagoas a 17,3\% no Amazonas, estando a média nacional em $8 \%$, e a mediana em $7 \%$. Além disso, a dispersão relativa $(\mathrm{cv}=0,41)$ era maior do que nos casos de rendimento $(\mathrm{cv}=0,37)$ e escolaridade $(\mathrm{cv}=0,16)$.

Em apenas seis UFs, a participação dos trabalhadores técnicos e científicos ultrapassava 10\% do total. São eles o Amazonas $(17,3 \%)$, o Rio de Janeiro (15,1\%), o Distrito Federal (13,2\%), São Paulo (13,1\%), o Espírito Santo $(10,96 \%)$ e a Bahia $(10,2 \%)$. Os valores mais freqüentes giravam entre $6 \%$ e $8 \%$, faixa de ocorrência em onze Estados.

Com relação às regiões, os Estados das regiões Sul e Sudeste voltam a apresentar os melhores resultados, ainda que o $\mathrm{Pa}$ raná e o Rio Grande do Sul $(7,9 \%$ ) apresentem valores bem abaixo dos encontrados em UF como Amazonas (17,3\%), Distrito Federal $(13,2 \%)$, Bahia $(10,2 \%)$ e Sergipe $(8,1 \%)$. Como nas demais variáveis, os piores resultados ocorrem nas regiões Norte, Nordeste e Centro-Oeste, salvo as exceções mencionadas acima.

\section{2_Associação entre as variáveis}

A análise empreendida até aqui procurou esboçar as principais características da indústria com relação às variáveis remuneração, escolaridade, participação de trabalhadores técnicos e científicos, emprego e estabelecimentos numa perspectiva unidimensional, isto é, observando cada característica isoladamente.

Nesta seção, o objetivo é ampliado no sentido de poder analisar "o comportamento global" das atividades industriais em cada região. O processo de análise assume caráter multidimensional, buscando, ainda que de forma exploratória, evidenciar padrões de desenvolvimento industrial das diferentes Unidades da Federação.

A primeira observação sobre a matriz de correlações (Tabela 2) destaca que, dos dez pares possíveis, seis são significativos ao nível de $1 \%$. Confirmando as observações anteriores, a maior associação ocorre entre o número de empregos e o de estabelecimentos $(0,986)$. Seguem-se participação de trabalhadores técnicos, científicos e remuneração $(0,890)$, participação de trabalhadores técnicos, científicos e escolaridade $(0,770)$, escolaridade e remuneração $(0,636)$, remuneração e número de empregos $(0,583)$ e remuneração e número de estabelecimentos $(0,572)$. 
Tabela 2_Correlações entre as variáveis das Unidades da Federação

\begin{tabular}{|c|c|c|c|c|c|}
\hline Variáveis & $\begin{array}{l}\text { Remune- } \\
\text { ração }\end{array}$ & $\begin{array}{c}\text { Escolari- } \\
\text { dade }\end{array}$ & Técnicos & $\begin{array}{c}\mathrm{N}^{0} \text { de } \\
\text { empregados }\end{array}$ & $\begin{array}{l}\text { estabele- } \\
\text { cimentos }\end{array}$ \\
\hline Remuneração & 1 & $0,633^{2}$ & $0,890^{2}$ & $0,583^{2}$ & $0,572^{2}$ \\
\hline Escolaridade & & 1 & $0,770^{2}$ & 0,308 & 0,3361 \\
\hline Técnicos & & & 1 & $0,364^{1}$ & $0,350^{1}$ \\
\hline $\mathrm{N}^{\mathrm{o}}$ de empregados & & & & 1 & $0,986^{2}$ \\
\hline $\begin{array}{l}N^{o} \text { de estabelecimentos } \\
\text { (1) correlação significativa a } \\
\text { (2) correlação significativa a }\end{array}$ & $\begin{array}{l}\text { el de } 5 \% \\
\text { el de } 1 \%\end{array}$ & & & & $1 \ldots$ \\
\hline
\end{tabular}

Uma leitura dessas associações indica que a região onde a indústria paga maior remuneração tende a apresentar maior participação de trabalhadores técnicos e científicos, maior escolaridade da mão-de-obra, ter maior volume de emprego e maior número de estabelecimentos. Em outras palavras, a região mais desenvolvida em termos industriais seria efetivamente aquela onde o numero de estabelecimentos e de emprego é maior, e o nivel de remuneração, de escolaridade e de profissionais técnicos e científicos é mais elevado.

\subsection{Ordenação das Unidades da Federação com base no Índice de Desenvolvimento Industrial}

Conforme informado anteriormente, a obtenção do índice para ordenar as regiões segundo o seu desempenho nas cinco variáveis utilizadas é feita com base na primeira componente fornecida pelo método da ACP $\left(C_{1}\right)$. Para as Unidades da Federação, obteve-se uma (primeira) componente que explica $67 \%$ da variância total dos dados (no caso, as cinco variáveis). O Índice de Desenvolvimento Industrial resulta da aplicação das seguintes ponderações aos valores padronizados das cinco variáveis:

1. Remuneração

2. Escolaridade

3. Percentual de trabalhadores técnicos e científicos

4. Número de empregos

5. Número de estabelecimentos 
O índice obtido pela ACP tem média zero e desvio padrão igual a um. Assim, valores do índice próximos a zero indicam valores "na média". Maiores valores positivos corresponderão às regiões "mais desenvolvidas" industrialmente, ao passo que valores mais negativos representam regiões "menos desenvolvidas". Calculando-se os valores do índice para as 27 Unidades da Federação, consegue-se ordená-las conforme mostra a Tabela 3.

Os valores do índice variam de 3,30 em São Paulo a -1,48 em Alagoas. Apenas dez Estados obtiveram valores positivos (acima da média). Dentre esses, o destaque cabe a São Paulo, cujo valor $(3,30)$ é mais do que o dobro do Rio de Janeiro $(1,61)$ e do Amazonas (1,38). Este último representa certa surpresa, superando os demais Estados das regiões Sul e Sudeste. Note-se que o nível de escolaridade e o percentual de trabalhadores técnicos e científicos do Amazonas é o mais alto do País. Tal fato se explica pela concentração de trabalhadores de ramos relativamente modernos da indústria metal-mecânica e eletroeletrônica na Zona Franca de Manaus.

Abaixo desses valores, encontramos ainda sete Estados com valores positivos variando de 0,81 para Minas Gerais a 0,43 para o Espírito Santo, formando um continuиm que sugere uma relativa "homogenei- dade" da indústria nessas regiões. A exceção do Distrito Federal $(0,63)$ e da Bahia $(0,48)$, esses Estados pertencem às regiões Sul e Sudeste.

No extremo oposto, o destaque negativo ocorre para Alagoas $(-1,48)$, enquanto a seqüência de 16 valores negativos começando com Goiás $(-0,15)$ até o Acre $(-1,03)$ - forma um conjunto de regiões “menos desenvolvidas". Esses Estados pertencem às regiões Norte, Nordeste e Centro-Oeste.

\subsection{1_ Entendendo mais as diferenças regionais:} a informação da componente $\mathrm{C}_{2}$

Explorando um pouco mais o potencial descritivo da ACP, é possível representar as 27 Unidades da Federação como pontos no plano formado pelas duas primeiras componentes principais. A primeira componente é aquela que forneceu o índice, e, como dito, responde por $67 \% \mathrm{da}$ variância total. A segunda componente explica $25 \%$ da variância, o que possibilita representar $92 \%$ da variância total no plano $C_{1} \times C_{2}$. As ponderações na segunda componente são as seguintes:

- Remuneração $\quad-0,161$

- Escolaridade -0,389

- Percentual de trabalhadores técnicos e científicos $\quad-0,396$

- Número de empregos $\quad 0,486$

- Número de estabelecimentos $\quad 0,484$ 
Tabela 3_ Unidades da Federação ordenadas pelo índice (ACP)

\begin{tabular}{|c|c|c|c|c|c|c|}
\hline Unidades da Federação & $\begin{array}{c}\text { Remuneração } \\
\text { (R\$) }\end{array}$ & $\begin{array}{c}\text { Escolaridade } \\
\text { (anos) }\end{array}$ & $\begin{array}{l}\text { Técnicos } \\
\text { (\%) }\end{array}$ & $\begin{array}{c}N^{\circ} \text { de } \\
\text { empregados }\end{array}$ & $\begin{array}{c}\mathrm{N}^{\circ} \text { de } \\
\text { estabelecimentos }\end{array}$ & Índice \\
\hline São Paulo & 1.401 & 9,2 & 13,1 & 2.078 .525 & 79.854 & 3,30 \\
\hline Rio de Janeiro & 1.492 & 9,0 & 15,1 & 323.921 & 14.381 & 1,61 \\
\hline Amazonas & 1.142 & 10,5 & 17,3 & 86.236 & 1.304 & 1,38 \\
\hline Minas Gerais & 823 & 8,2 & 9,0 & 629.321 & 35.335 & 0,81 \\
\hline$\underline{\text { Rio Grande do Sul }}$ & 894 & 8,2 & 7,9 & 620.639 & 31.493 & 0,73 \\
\hline$\underline{\text { Distrito Federal }}$ & 976 & 9,2 & 13,2 & 18.588 & 1.588 & 0,63 \\
\hline Paraná & 813 & 8,6 & 7,9 & 482.259 & 24.417 & 0,55 \\
\hline Santa Catarina & 798 & 8,4 & 8,1 & 482.931 & 24.549 & 0,52 \\
\hline Bahia & 985 & 8,7 & 10,2 & 148.102 & 7.533 & 0,48 \\
\hline Espírito Santo & 920 & 8,7 & 11,0 & 97.321 & 5.732 & 0,43 \\
\hline Goiás & 635 & 8,3 & 7,1 & 135.717 & 8.641 & $-0,15$ \\
\hline Sergipe & 849 & 7,4 & 8,1 & 29.116 & 1.340 & $-0,20$ \\
\hline Amapá & 732 & 7,8 & 7,0 & 2.779 & 231 & $-0,36$ \\
\hline Rio Grande do Norte & 672 & 7,7 & 6,6 & 55.095 & 2.346 & $-0,40$ \\
\hline Ceará & 488 & 8,1 & 5,8 & 176.854 & 6.871 & $-0,44$ \\
\hline Mato Grosso & 644 & 7,4 & 6,4 & 72.248 & 4.319 & $-0,47$ \\
\hline Pernambuco & 647 & 6,7 & 6,8 & 147.209 & 6.547 & $-0,47$ \\
\hline Mato Grosso do Sul & 601 & 7,8 & 5,9 & 48.391 & 2.427 & $-0,51$ \\
\hline Maranhão & 583 & 7,5 & 7,1 & 23.190 & 1.477 & $-0,52$ \\
\hline Pará & 668 & 6,5 & 6,3 & 90.479 & 3.242 & $-0,61$ \\
\hline Piauí & 431 & 7,6 & 7,0 & 20.777 & 1.514 & $-0,65$ \\
\hline Roraima & 471 & 7,7 & 6,4 & 1.523 & 170 & $-0,67$ \\
\hline Paraíba & 488 & 7,2 & 5,7 & 51.153 & 2.384 & $-0,74$ \\
\hline Tocantins & 474 & 7,7 & 4,1 & 8.702 & 775 & $-0,84$ \\
\hline Rondônia & 498 & 7,0 & 4,6 & 25.945 & 1.831 & $-0,87$ \\
\hline Acre & 474 & 6,4 & 4,8 & 3.644 & 353 & $-1,03$ \\
\hline Alagoas & 520 & 3,6 & 4,0 & 94.916 & 1.156 & $-1,48$ \\
\hline
\end{tabular}

Fonte: Processamento dos autores a partir dos dados da RAIS 2004. 
Podemos observar que, na componente $C_{2}$, o maior peso ocorre nas duas variáveis que indicam a densidade das estruturas industriais na Unidade da Federação, sendo essa sua principal característica. Isto é, os maiores valores de $C_{2}$ ocorrem para as UFs com maiores número de empregos e de estabelecimentos. As outras três variáveis possuem pesos menores (em valor absoluto), sendo, portanto, menos importantes na composição dessa componente. Os sinais negativos para essas três variáveis indicam que, entre as UFs semelhantes quanto ao número de empregos e de estabelecimentos, apresentarão maiores valores de $\mathrm{C}_{2}$ os Estados com baixa escolaridade, reduzido percentual de trabalhadores técnicos e pequena remuneração (observa-se, na componente $C_{2}$, a remuneração tem o menor peso em valor absoluto).

Fazendo a leitura da Figura 1, a seguir, é possível perceber duas UFs isoladas (São Paulo e Alagoas) e alguns grupos de UFs com valores para $C_{1}$ e $C_{2}$ não muito diferentes. A informação adicional que esse gráfico fornece é a distinção entre unidades que estão muito próximas na ordenação em $C_{1}$, e que aparecem agora separadas.

\section{Figura 1_Gráfico C1 × C2 para as Unidades da Federação}

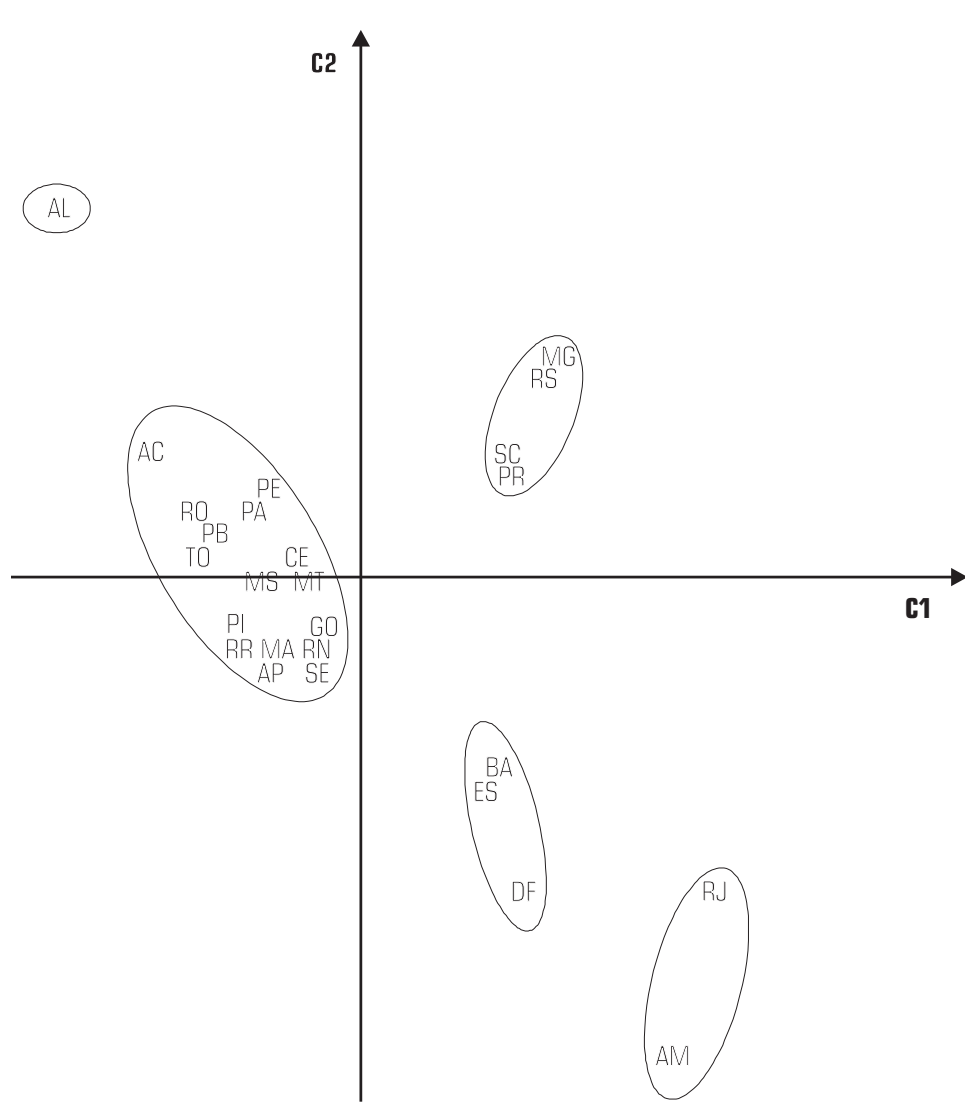

Fonte: Processamento dos autores a partir dos dados da RAIS 2004. 
6 Como mencionado na seção 2.5, foi utilizado um método hierárquico, o método de Ward, com as cinco variáveis padronizadas.
Analisando o primeiro e o quarto quadrantes (valores positivos para $C_{1}$, concentrando nossa atenção nos valores de $C_{2}$, vemos que São Paulo continua destacado das demais, graças agora ao número de empregos e estabelecimentos que é muitíssimo mais alto que as demais Unidades. Vemos também Rio de Janeiro, Amazonas, Bahia, Espírito Santo e Distrito Federal com valores bastante baixos em $C_{2}$ por causa do menor tamanho e também dos seus valores altos em escolaridade, remuneração e percentual de técnicos. Já Minas Gerais e Rio Grande do Sul aparecem com sinal positivo em $C_{2}$ em razão, provavelmente, de sua extensão geográfica. Santa Catarina e Paraná, com valores positivos, porém mais baixos, apresentam menores valores para número de empregos e número de estabelecimentos, se comparadas com Minas Gerais e Rio Grande do Sul.

Considerando os segundo e terceiro quadrantes (negativos em $C_{1}$ ), encontramos Alagoas, que obteve o segundo maior valor em $C_{2}$ por causa da sua baixa remuneração, escolaridade e percentual de técnicos e número de empregos relativamente alto em comparação com as demais Unidades que possuem valores negativos de $C_{1}$. As demais UFs desses dois quadrantes aparecem próximas entre si. Observa-se para esse grupo de 16 Unidades que os mais al- tos valores em $C_{2}$ correspondem aos mais baixos em $C_{1}$ e vice-versa.

\section{4_Padrões de desenvolvimento industrial semelhantes: Análise de Grupamento}

O objetivo nesta seção é identificar a existência (ou não) de padrões de desenvolvimento industrial semelhantes entre as 27 Unidades da Federação com base nas mesmas cinco variáveis utilizadas na criação do índice. Para esse fim, vamos utilizar a técnica de Análise de Grupamento (AG).

O resultado da aplicação da técnica ${ }^{6}$ aparece na Figura 2 a seguir. Este diagrama em forma de árvore (dendrograma) apresenta na sua base as 27 UFs consideradas individualmente (nível de agregação zero). Cada nó da arvore (junção) representa a formação de um novo grupamento (uma nova agregação). No eixo horizontal, medese a distância (entre os grupos) obtida pelo método que representa o "grau de semelhança”" entre os grupos que foram agregados naquele nó (estágio).

Podemos notar, inicialmente, a nítida separação das 27 UFs em dois grupos distintos. O primeiro é formado por 17 Estados (incluindo também o Distrito Federal) e corresponde exatamente àquelas regiões que apresentaram valores negativos no índice da ACP. 


\section{Figura 2_Análise de Grupamento - Unidades da Federação}

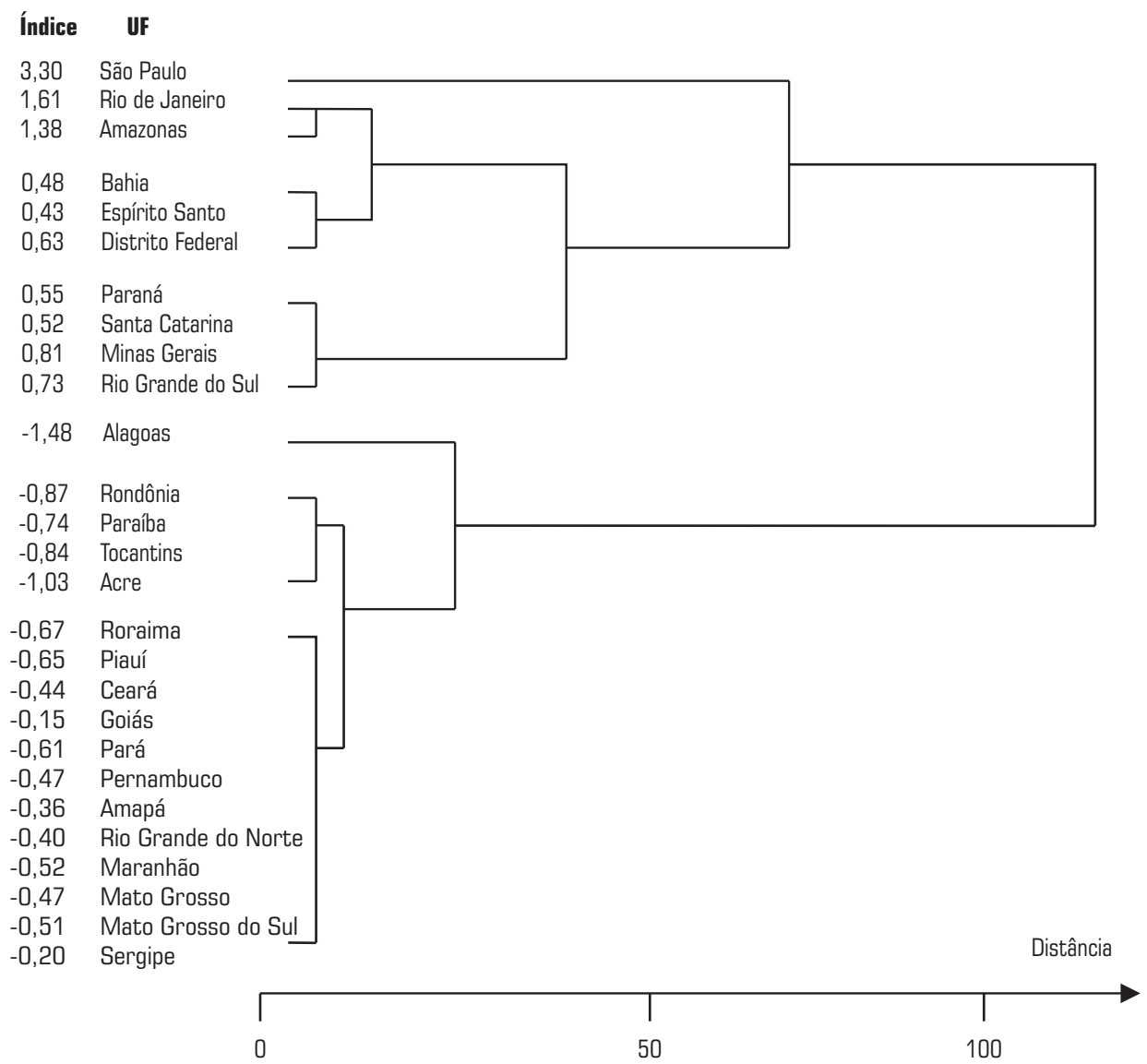

Fonte: Processamento dos autores a partir dos dados da RAIS 2004. 
O grupo apresenta bastante semelhança entre seus elementos, à exceção de Alagoas. Isso pode ser constatado observando-se como são relativamente baixos os valores das distâncias onde ocorrem as agregações que formam o grupo. Esse resultado já havia aparecido no Gráfico $C_{1} \times C_{2}$, no qual chamamos a atenção para o isolamento de Alagoas entre as unidades com $C_{1}<0$.

Já o segundo grupo, composto pelas outras dez Unidades da Federação, apresenta valores positivos do índice. Vale notar, aqui, que nesse caso há "maior heterogeneidade" entre seus elementos. Primeiramente, São Paulo destaca-se de forma nítida, sendo a última agregação feita, em nível bem elevado. Podemos mesmo aprofundar a observação e notarmos subdivisões internas, com a presença de dois subgrupos. Um formado por Paraná, Santa Catarina, Minas Gerais e Rio Grande do Sul; o outro, por Bahia, Espírito Santo, Distrito Federal, Amazonas e Rio de Janeiro. Observe-se que o primeiro diferencia-se do segundo por apresentar uma indústria de maior dimensão (mais empregos e estabelecimentos). Este último grupo ainda comportaria outra "quebra", destacando Rio de Janeiro e Amazonas, cujos indicadores são bem melhores que os encontrados na Bahia, no Espírito Santo e no Distrito Fede- ral. Cabe salientar que essas subdivisões estão em perfeita sintonia com a análise do Gráfico $C_{1} \times C_{2}$, confirmando-se aqui os resultados apontados anteriormente.

\section{4_Análise das mesorregiões}

No sentido de aprofundar a análise regional, passamos a seguir a examinar as mesmas variáveis (remuneração, escolaridade, percentual de trabalhadores técnicos e científicos, número de empregos e de estabelecimentos) para as 137 mesorregiões brasileiras. O principal objetivo aqui é obter um mapa mais detalhado dos diferentes níveis de desenvolvimento industrial do País. Esse refinamento tornase necessário na medida em que, como destacado na revisão da literatura, a distribuição espacial da estrutura industrial no Brasil apresenta-se de forma bastante heterogênea. Heterogeneidade essa que nem sempre é visualizada em toda a sua extensão quando trabalhamos com níveis de agregação como no caso das grandes regiões, ou mesmo das Unidades federativas.

O processo de análise apresenta a mesma estrutura desenvolvida anteriormente, isto é, construção do Índice de Desenvolvimento Industrial (via ACP), seguida de Análise de Grupamento para identificar mesorregiões com perfis industriais seme- 
lhantes. Antes de apresentarmos os resultados para os índices, vale a pena dar uma rápida revisada nas estatísticas descritivas das variáveis e suas correlações.

\section{1_Principais estatísticas}

Comparando a Tabela 4 com a Tabela 1 , observamos que as mudanças mais relevantes ocorreram para as variáveis "número de empregados" e "número de estabelecimentos", que apresentam valores médios bem menores, o que já era esperado, já que o nível de agregação dos dados agora é menor. Observa-se ainda uma pequena queda nos valores médios da "remuneração" e "percentual de trabalhadores técnicos e científicos", os quais apresentam desvios padrão ligeiramente mais altos.
Essas mudanças também podem ser explicadas pela desagregação dos dados, que permite que as diferenças dentro de cada Unidade da Federação apareçam.

Por outro lado, a comparação entre as Tabelas 2 e 5 mostra que os coeficientes de correlação estimados são bastante próximos, embora, na segunda análise, graças ao maior número de casos (137), todos os coeficientes são significativos ao nível de $1 \%$. Do ponto de vista descritivo, no entanto, podemos dizer que a estrutura das correlações é praticamente a mesma para as duas bases de dados. Esse fato reflete-se na construção do índice, que, como veremos a seguir, apresenta praticamente as mesmas ponderações da análise anterior.

Tabela 4_Estatísticas descritivas - mesorregióes

\begin{tabular}{|c|c|c|c|c|}
\hline Variáveis & Mínimo & Máximo & Média & Desvio padrão \\
\hline Remuneração (R\$) & 308 & 3.200 & 705 & 368 \\
\hline Escolaridade (anos) & 3,5 & 10,5 & 7,7 & 1,2 \\
\hline Técnicos $(\%)$ & 0 & 23,9 & 7,1 & 4,1 \\
\hline $\mathrm{N}^{\circ}$ de empregados & 6 & 969.558 & 43.415 & 95.931 \\
\hline $\mathrm{N}^{o}$ de estabelecimentos & 3 & 38.446 & 1.982 & 3.938 \\
\hline
\end{tabular}

Fonte: Processamento dos autores a partir dos dados da RAIS 2004. 
Tabela 5_Correlações entre as variáveis das mesorregiões

\begin{tabular}{|c|c|c|c|c|c|}
\hline Variáveis & $\begin{array}{l}\text { Remune- } \\
\text { ração }\end{array}$ & $\begin{array}{l}\text { Escolari- } \\
\text { dade }\end{array}$ & Técnicos & $\begin{array}{c}N^{0} \text { de } \\
\text { empregados }\end{array}$ & $\begin{array}{c}\mathrm{N}^{0} \text { de } \\
\text { estabelecimentos }\end{array}$ \\
\hline Remuneração & 1 & $0,584^{1}$ & $0,797^{1}$ & $0,412^{1}$ & $0,369^{1}$ \\
\hline Escolaridade & & 1 & $0,640^{1}$ & $0,318^{1}$ & $0,336^{1}$ \\
\hline Técnicos & & & 1 & $0,351^{1}$ & $0,318^{1}$ \\
\hline $\mathrm{N}^{\circ}$ de empregados & & & & 1 & $0,983^{1}$ \\
\hline $\mathrm{N}^{o}$ de estabelecimentos & & & & & 1 \\
\hline
\end{tabular}

(1) correlação significativa ao nível de $1 \%$

Fonte: Processamento dos autores a partir dos dados da RAIS 2004.

\section{2_Ordenação das mesorregiões}

A análise das componentes principais fornece uma primeira componente que descreve $61 \%$ da variância total. O índice obtido utilizará as seguintes ponderações aos valores (padronizados) das variáveis:

- Remuneração

- Escolaridade

- Percentual de trabalhadores técnicos e científicos

- Número de empregos

- Número de estabelecimentos

0,252

As informações sobre as cinco variáveis utilizadas e a ordenação das 137 mesorregiões estão apresentadas no anexo ao final do artigo.
Os valores variam de 6,36 (Metropolitana de São Paulo) a -1,54 (Marajó). Das 137 regiões, 51 apresentam valores positivos para o índice (maiores que a média), representando regiões "mais desenvolvidas", enquanto as outras 86 , com índices negativos, associam-se às "menos desenvolvidas". A Figura 3 ilustra a distribuição do índice para as 137 mesorregiões.

A primeira observação é sobre o desempenho da Região Metropolitana de São Paulo, que apresenta um valor para o índice $(6,36)$ duas vezes maior que a segunda colocada, Norte Fluminense $(3,15)$. Se levarmos em consideração que o índice foi construído de forma a ter média zero e desvio padrão unitário, verificamos que a RM de São Paulo representa efetivamente um verdadeiro "ponto fora do gráfico". 
Figura 3_ Índice de Desenvolvimento Industrial - mesorregiões

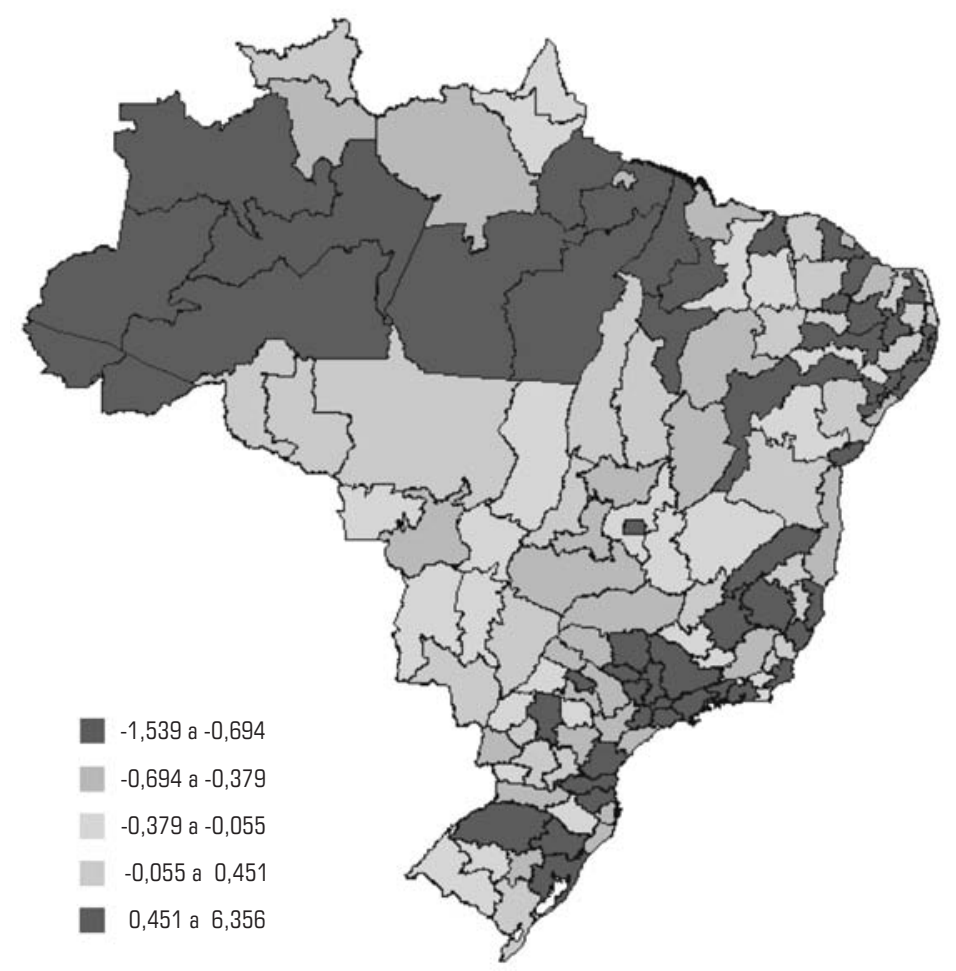

Fonte: Processamento dos autores a partir da tabela do Anexo.

Considerando a relação espacial em termos das grandes regiões, vemos que, das 51 mesorregiões com índice positivo, 22 pertencem à região Sudeste: 12 são de São Paulo, 5 de Minas Gerais, 3 do Rio de Janeiro e 2 do Espírito Santo. Vale lembrar que 37 mesorregiões compõem a região Sudeste.

A região Sul possui 23 mesorregiões, entre as quais, 12 apresentam índices positivos - 5 em Santa Catarina, 4 no Paraná e 3 no Rio Grande do Sul.

Desta forma, as regiões Sul e Sudeste respondem por 34 das 51 mesorregiões mais desenvolvidas (índice positivo). As restantes 17 mesorregiões distribuem-se da seguinte forma: 3 na região Norte, 9 na região Nordeste, e 5 na região Centro-Oeste. São elas: Centro Amazonense $\left(10^{a}=1,63\right)$, 
Metropolitana de Salvador $\left(11^{\mathrm{a}}=1,57\right)$, Distrito Federal $\left(20^{\mathrm{a}}=0,80\right)$, Metropolitana do Recife $\left(24^{a}=0,53\right)$, Centro Goiano $\left(29^{a}=0,45\right)$, Metropolitana de Fortaleza $\left(31^{a}=0,40\right)$, Norte Maranhense $\left(37^{a}=0,31\right)$, Norte Goiano $\left(38^{a}=0,31\right)$, Baixo Amazonas-PA $\left(39^{\mathrm{a}}=0,30\right)$, Extremo Oeste Baiano $\left(40^{a}=0,22\right)$, Leste Sergipano $\left(42^{a}=0,12\right)$, Sudoeste Piauiense $\left(44^{\mathrm{a}}=0,12\right)$, Sul Goiano $\left(45^{a}=0,10\right)$, Oeste Potiguar $\left(46^{a}=0,09\right)$, Sul Baiano $\left(47^{\mathrm{a}}=0,08\right)$, Centro-Sul MatoGrossense $\left(48^{a}=0,07\right)$ e Metropolitana de Belém $\left(49^{\mathrm{a}}=0,07\right)$.

Oito Unidades da Federação não possuem sequer uma mesorregião "desenvolvida": Acre, Amapá, Rondônia, Roraima e Tocantins na região Norte; Alagoas e Paraíba na região Nordeste; e Mato Grosso do Sul na região Centro-Oeste.

Por fim, vale ressaltar que todas as nove regiões metropolitanas apresentam índices positivos: além do destaque de São Paulo, seguem-se Rio de Janeiro $\left(4^{a}=2,34\right)$, Porto Alegre $\left(6^{\mathrm{a}}=1,88\right)$, Belo Horizonte $\left(7^{\mathrm{a}}=1,84\right)$, Curitiba $\left(8^{\mathrm{a}}=1,77\right)$, Salvador $\left(11^{a}=1,57\right)$, Recife $\left(24^{a}=0,53\right)$, Fortaleza $\left(31^{\mathrm{a}}=0,40\right)$ e Belém $\left(49^{\mathrm{a}}=0,07\right)$.

Das 86 mesorregiões com valores negativos no índice, 17 estão na região Norte, 33 na região Nordeste, 10 na Centro-Oeste, 11 na Sul e 15 na Sudeste. Merecem destaque negativo, entre aquelas pertencentes às regiões Sul e Sudeste, as seguintes mesorregiões: Jequitinhonha $\left(126^{a}=-0,95\right)$ e Vale do Mucuri $\left(110^{\mathrm{a}}=-0,67\right)$, em Minas Gerais; Centro Ocidental Paranaense $\left(100^{\mathrm{a}}=-0,58\right)$, Sudeste Paranaense $\left(98^{a}=-0,56\right)$ e CentroSul Paranaense $\left(96^{a}=-0,51\right)$, no Paraná.

Em resumo, as mesorregiões com índice negativo concentram-se nas regiões Norte (17 em 20), Nordeste (33 em 42), Centro-Oeste (10 em 15). Na região Sul, temos 11 (em 23), e na Sudeste, 15 (em 37).

\subsection{1_A informação da segunda componente}

Abaixo apresentamos o gráfico de $C_{1} \mathrm{e}$ $C_{2}$ na Figura 4, que contém 137 pontos correspondentes às mesorregiões brasileiras, cujas coordenadas são os valores da primeira componente (que forneceu o índice, com $61 \%$ da variância total) e da segunda componente (que contém $26 \%$ da variância). As ponderações das variáveis na segunda componente são:

- Remuneração

- Escolaridade $-0,301$

- $\%$ de trabalhadores técnicos e científicos

- Número de empregos 0,475

- Número de estabelecimentos $\quad 0,491$

Nota-se que as ponderações são muito parecidas com aquelas da análise para as Unidades da Federação. Sua interpretação é análoga à realizada anteriormente. 
Figura 4_Gráfico $C_{1} \times C_{2}$ para as mesorregiões

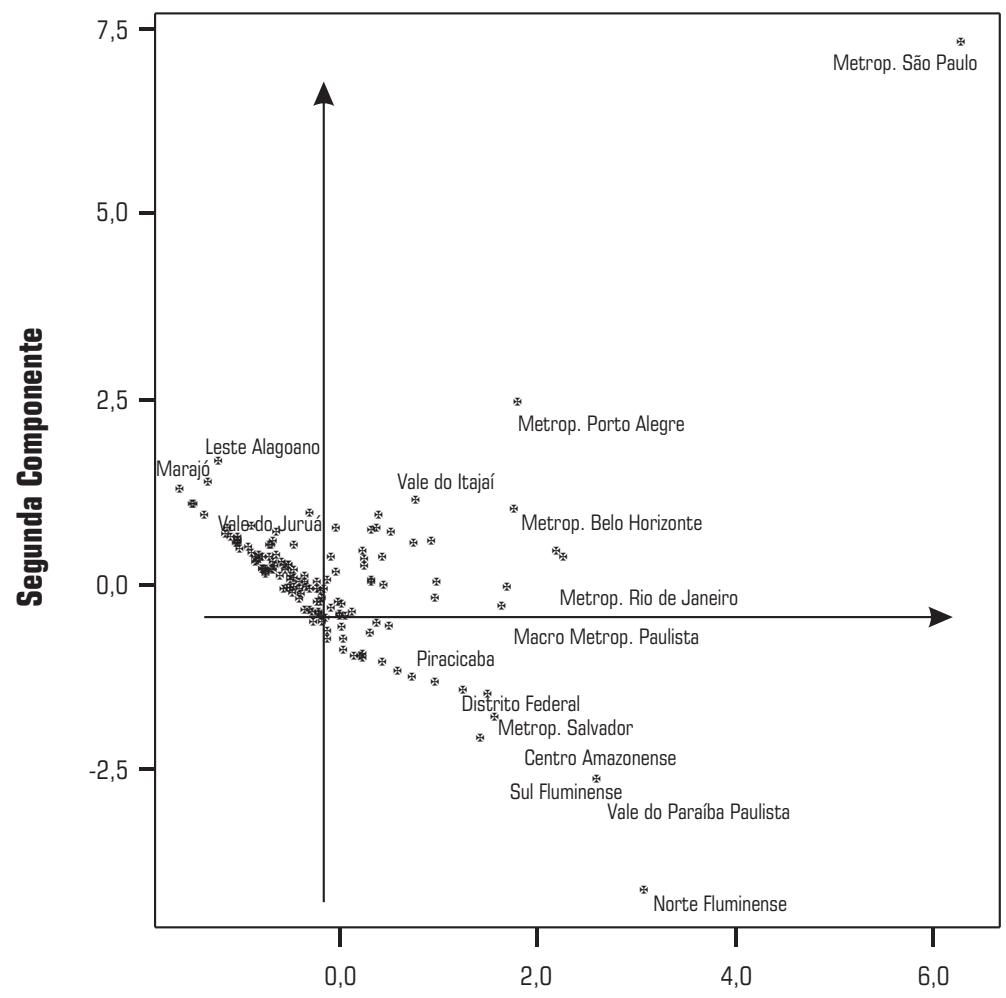

\section{Primeira Componente}

Fonte: Processamento dos autores a partir dos dados da RAIS 2004.

O gráfico mostra uma nuvem densa de pontos muito próximos formando um caminho descendente do segundo para o quarto quadrante, com algumas regiões fora desse caminho, sendo o destaque principal a Região Metropolitana de São Paulo. Ob- servamos, entretanto, que o espalhamento na direção de $C_{2}$ é muito maior para os valores positivos de $C_{1}$. Em outras palavras,
se $C_{1}<0, C_{2} \in(-1,1,45)$
se $C_{1}>0, C_{2} \in(-4,5,7,5)$ 
Podemos dizer que a segunda componente mostra melhor as diferenças entre as mesorregiões cujos valores da primeira componente (índice) são positivos. Na impossibilidade de fazer a análise para as 137 mesorregiões que estão no gráfico acima, comentaremos algumas regiões entre as que se destacam na figura.

Considerando, por exemplo, o primeiro e quarto quadrantes, podemos assinalar a Norte Fluminense, Vale do Paraíba Paulista, Sul Fluminense, Centro Amazonense, Vale do Rio Doce, Salvador, Distrito Federal, etc., que estão em oposição a Porto Alegre, Belo Horizonte, Rio de Janeiro, Campinas, etc., principalmente, em razão das diferenças de tamanho e, secundariamente, das diferenças nas variáveis renda, escolaridade, percentual de técnicos.

Olhando o segundo quadrante, é possível distinguir, entre outras, a Leste Alagoano, a Mata Pernambucana e a Marajó. De fato, consultando a tabela do anexo, observa-se que essas regiões apresentam valores muito baixos para renda, escolaridade e percentual de técnicos.

Finalizando, podemos dizer que o Gráfico $C_{1} \times C_{2}$ fornece uma visão de conjunto das 137 mesorregiões. Uma análise mais detalhada será feita a seguir utilizando-se a Análise de Grupamento.

\section{3_Análise das semelhanças e diferenças entre mesorregióes}

$O$ resultado da seção anterior permite concluir que as diferenças mais importantes, no que se refere ao conjunto das cinco variáveis, estão associadas às mesorregiões que apresentaram o valor do índice $C_{1}$ positivo. Por isso, a análise de semelhanças e diferenças focalizará essas 51 mesorregiões. Examinando os índices para essas mesorregiões, destaca-se a Região Metropolitana de São Paulo com um valor muito acima das demais, podendo ser considerada como um caso isolado. Por essa razão, essa região será retirada da Análise de Grupamento. Continuando a examinar os valores dos índices, observa-se um pequeno salto entre a vigésima $\left(C_{1}=0,80\right)$ e a vigésima primeira $\left(C_{1}=0,66\right)$. Logo, para melhor visualização dos resultados, serão feitas duas Análises de Grupamento: uma incluindo as 19 melhores, e outra, as 31 restantes.

A primeira Análise de Grupamento, incluindo as 19 mesorregiões com índices mais elevados (excluindo a Metropolitana de São Paulo), foi realizada usando-se o método de Ward, com base nas cinco variáveis padronizadas. $\mathrm{O}$ resultado está na Figura 5. 


\title{
Figura 5_Análise de Grupamento - 19 mesorregióes
}

\author{
1,04 Piracicaba \\ 1,06 Norte Catarinense \\ 1,00 Nordeste Rio-Grandense \\ 0,82 Ribeirão Preto \\ 0,83 Vale do Itajaí \\ 1,72 Macro Metrop. Paulista \\ 1,77 Metropol. De Curitiba \\ 2,34 Metropol. Rio de Janeiro \\ 2,26 Campinas \\ 1,84 Metrop. Belo Horizonte \\ 1,88 Metrop. Porto Alegre
}

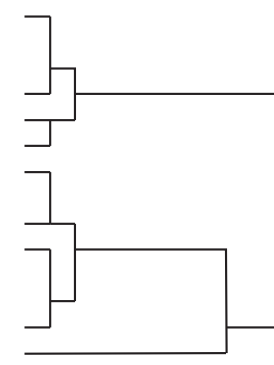

1,04 Vale do Rio Doce

0,80 Distrito Federal

1,57 Metropol de Salvador

1,32 Central Espírito-Santense

1,49 Sul Fluminense

1,63 Centro Amazonense

2,67 Vale Paraíba Paulista

3,15 Norte Fluminense
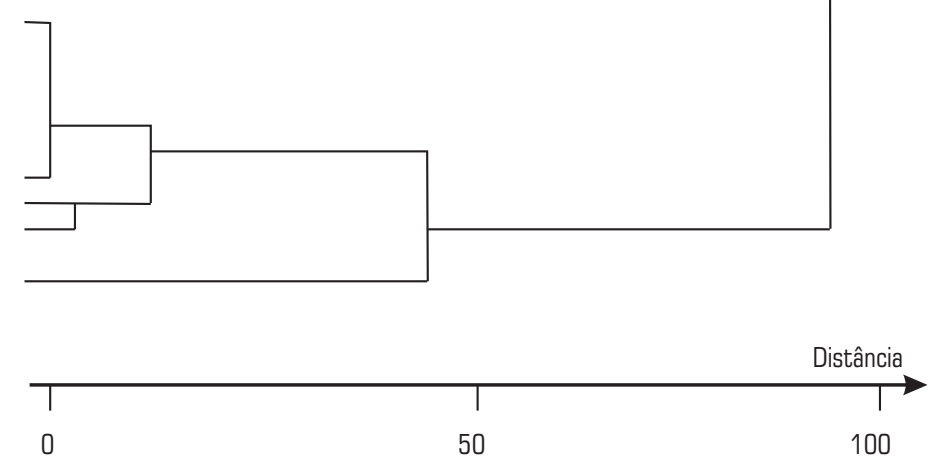

Fonte: Processamento dos autores a partir dos dados da RAIS 2004.

Observa-se a formação de dois grupos. O primeiro, denominado Grupo 1, que inclui as seguintes 11 mesorregiões: Piracicaba, Norte Catarinense, Nordeste RioGrandense, Ribeirão Preto, Vale do Itajaí, Macro Metropolitana Paulista, Metropolitana de Curitiba, Metropolitana do Rio de Janeiro, Campinas, Metropolitana de Belo Horizonte e Metropolitana de Porto Alegre. O Grupo 2 é formado por oito mesor- regiões, incluindo Vale do Rio Doce, Distrito Federal, Metropolitana de Salvador, Central Espírito-Santense, Sul Fluminense, Centro Amazonense, Vale do Paraíba Paulista e Norte Fluminense. Para melhor analisar as diferenças apontadas pela Análise de Grupamento, vamos apresentar as estatísticas descritivas das cinco variáveis dentro de cada grupo. 
Tabela (6a)_Estatísticas descritivas - Grupo 1

\begin{tabular}{|c|c|c|c|c|}
\hline Variáveis & Mínimo & Máximo & Média & Desvio padrão \\
\hline Remuneração & 762 & 1.438 & 1.109 & 216 \\
\hline Escolaridade & 8,0 & 9,4 & 8,7 & 0,51 \\
\hline Técnicos & 7,7 & 15,0 & 10,9 & 2,6 \\
\hline $\mathrm{N}^{\mathrm{o}}$ Empregados & 109.445 & 312.681 & 182.191 & 63.137 \\
\hline $\mathrm{N}^{\mathrm{o}}$ Estabelecimentos & 4.188 & 14.066 & 7.818 & 2.995 \\
\hline
\end{tabular}

Fonte: Processamento dos autores a partir dos dados da RAIS 2004.

Tabela (6h)_Estatísticas descritivas - Grupo 2

\begin{tabular}{|c|c|c|c|c|}
\hline Variáveis & Mínimo & Máximo & Média & Desvio padrão \\
\hline Remuneração & 975 & 3.201 & 1.623 & 753 \\
\hline Escolaridade & 8,8 & 10,5 & 9,6 & 0,56 \\
\hline Técnicos & 13,2 & 23,9 & 16,9 & 3,5 \\
\hline $\mathrm{N}^{\circ}$ Empregados & 18.588 & 103.920 & 53.297 & 30.114 \\
\hline $\mathrm{N}^{\circ}$ Estabelecimentos & 748 & 2.810 & 1.765 & 778 \\
\hline
\end{tabular}

Fonte: Processamento dos autores a partir dos dados da RAIS 2004

Comparando-se os resultados, pode-se constatar que o primeiro grupo é caracterizado por ter, em média, menor remuneração, menor escolaridade, menor percentual de trabalhadores técnicos, e maior número de empregados e número de estabelecimentos. Observa-se que a maior di- ferença entre os dois grupos ocorre para as variáveis relacionadas com o tamanho da estrutura industrial (número de empregados e número de estabelecimentos). Vale observar que o valor máximo do "número de empregados" no grupo 2 (103.920) é menor que o valor mínimo para essa mes- 
ma variável no grupo 1 (109.445). Isso significa que todas as mesorregiões do grupo 2 têm "número de empregados" menor do que qualquer das mesorregiões do grupo 1. O mesmo ocorre para a variável "número de estabelecimentos”. Essa separação, tendo como critério o "tamanho", está de acordo com a descrição da componente $C_{2}$, que, como vimos, apresenta maior associação com essas duas variáveis.

A segunda Análise de Grupamento, incluindo as 31 mesorregiões restantes, com índice positivo, foi novamente realizada utilizando-se o método de Ward, com base nas cinco variáveis padronizadas. O resultado está na Figura 6.

\section{Figura 6_Análise de Grupamento - 31 mesorregióes com $0<$ índice $<0,7$}

\section{Índice Mesorregióes}

0,07 Metropolitana Belém

0,10 Sul Goiano

0,20 Centro Oriental Paranaense

0,04 Oeste Paranaense

0,07 Centro-Sul Mato-Grossense

0,09 Oeste Potiguar

0,12 Leste Sergipano

0,08 Sul Baiano

0,30 Baixo Amazonas

0,31 Norte Goiano

0,50 Litoral Norte Espírito Santo

0,38 Itapetininga

0,12 Litoral Sul Paulista

0,58 Araraquara

0,11 Sudoeste Piauiense

0,22 Extremo Oeste Baiano

0,31 Norte Maranhense

0,45 Grande Florianópolis

0,66 Marília

0,40 São José do Rio Preto

0,39 Bauru

0,31 Oeste Catarinense

0,33 Sul Catarinense

0,32 Triângulo Mineiro/Alto Paraníba

0,59 Sul/Sudoeste de Minas

0,51 Noroeste Rio-Grandense

0,53 Metropolitana de Recife

0,47 Norte Central Paraná

0,45 Centro Goiano

0,40 Metropolitana de Fortaleza

0,04 Zona da Mata
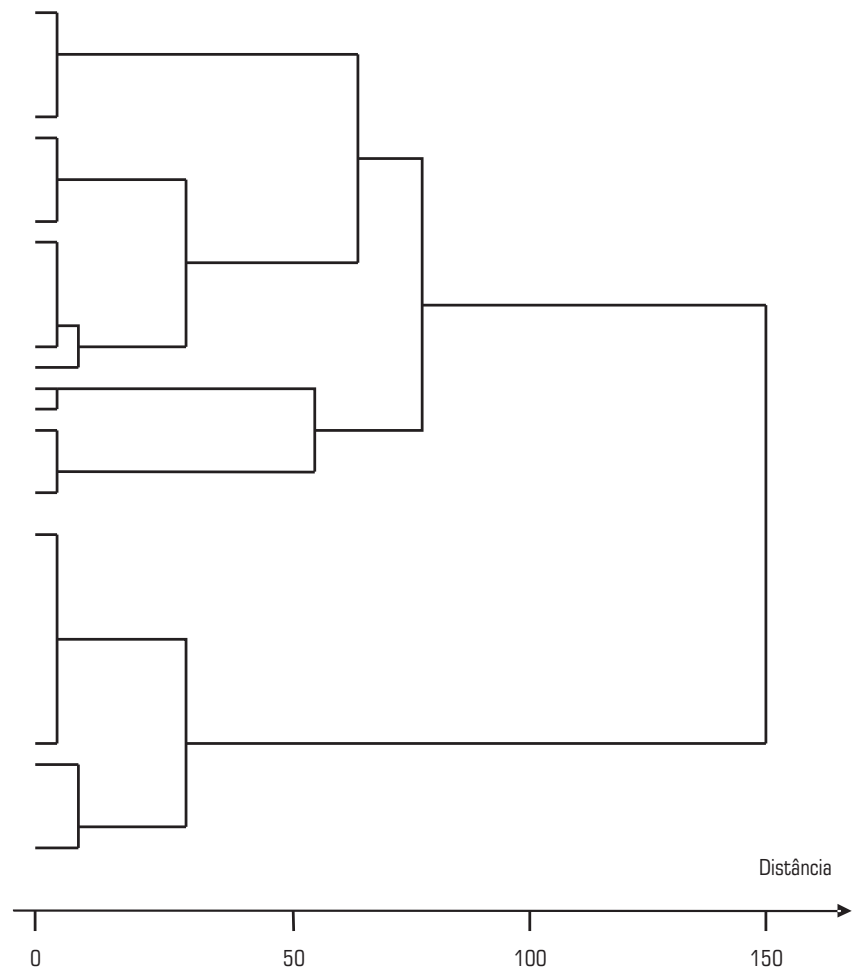

Fonte: Processamento dos autores a partir dos dados da RAIS 2004. 
Aqui também temos a divisão em dois grandes grupos, um com 12 mesorregiões (aqui denominado grupo 3, incluindo desde São José do Rio Preto até a Zona da Mata - veja Figura 6), outro com 19 me- sorregiões (grupo 4, começando com a Região Metropolitana de Belém até Marília veja Figura 6). As estatísticas descritivas das cinco variáveis dentro de cada grupo estão nas Tabelas (7a) e (7b).

Tabela (7a)_Estatísticas descritivas - Grupo 3

\begin{tabular}{|c|c|c|c|c|}
\hline Variáveis & Mínimo & Máximo & Média & Desvio padrão \\
\hline Remuneração & 530 & 844 & 686 & 97 \\
\hline Escolaridade & 7,6 & 8,6 & 8,3 & 0,27 \\
\hline Técnicos & 5,4 & 9,9 & 7,3 & 1,1 \\
\hline $\mathrm{N}^{\mathrm{o}}$ Empregados & 60.813 & 115.807 & 83.860 & 18.151 \\
\hline $\mathrm{N}^{\circ}$ Estabelecimentos & 2.905 & 6.392 & 4.628 & 1.201 \\
\hline
\end{tabular}

Fonte: Processamento dos autores a partir dos dados da RAIS 2004.

Tabela (7b)_Estatísticas descritivas - Grupo 4

\begin{tabular}{|c|c|c|c|c|}
\hline Variáveis & Mínimo & Máximo & Média & Desvio padrão \\
\hline Remuneração & 380 & 1.059 & 809 & 185 \\
\hline Escolaridade & 7,5 & 9,4 & 8,4 & 0,49 \\
\hline Técnicos & 5,8 & 13,4 & 9,3 & 2,0 \\
\hline $\mathrm{N}^{\mathrm{o}}$ Empregados & 982 & 53.518 & 20.921 & 15.716 \\
\hline $\mathrm{N}^{\circ}$ Estabelecimentos & 104 & 2.556 & 1.022 & 725 \\
\hline
\end{tabular}

Fonte: Processamento dos autores a partir dos dados da RAIS 2004

O grupo 4 apresenta renda média e percentual de trabalhadores técnicos um pouco mais elevados e número de empregos e de estabelecimentos muito menores que o grupo 3. Aqui novamente os grupos estão separados de modo que todas as mesor- 
regiões do grupo 4 apresentam "número de empregados" e "número de estabelecimentos" menores que qualquer das mesorregiões do grupo 3. Mais uma vez, o "tamanho" é o principal fator diferencial nesta análise.

Cabe aqui uma observação sobre os resultados obtidos nas duas Análises de Grupamento. O critério de escolha dos dois grupos (primeiro grupo: 19 primeiras colocadas segundo o índice; segundo grupo: 31 seguintes) seleciona mesorregiões cujos valores do índice são relativamente próximos. Este, por sua vez, é composto pelas cinco variáveis, sendo três que descrevem a qualidade da mão-de-obra, e duas que descrevem o tamanho do mercado de trabalho. Portanto, se duas mesorregiões são semelhantes quanto ao índice, ou são semelhantes em todas as variáveis, ou diferem de tal modo que a "média" (calculada pelo índice) resulta semelhante. Essas diferenças é que são captadas pela Análise de Grupamento. Nesse sentido, os resultados são esperados, isto é, as regiões diferem por apresentarem menos (ou mais) "qualidade" e, ao mesmo tempo, maior (ou menor) "tamanho".

Olhando os resultados estatísticos no seu conjunto, podemos afirmar que o principal fator para a classificação das regiões é bem representado pela primeira compo- nente principal, aqui utilizado como índice para a ordenação das mesorregiões. Conforme foi visto na seção anterior, esse inclui todas as variáveis praticamente com as mesmas ponderações. Por outro lado, a componente $C_{2}$ focaliza mais fortemente as variáveis "número de empregos" e "número de estabelecimentos", indicando que essas são as grandezas que diferenciam as regiões que apresentam valores semelhantes para o índice de desenvolvimento. As Análises de Grupamento realizadas nesta seção confirmam esse resultado, permitindo assim apontar o "tamanho" como segundo fator de distinção entre as mesorregiões.

\section{4_Diferenciação das mesorregiões nas Unidades da Federação}

Valendo-se dos resultados dos índices para mesorregiões, observa-se grande heterogeneidade dentro de algumas Unidades da Federação. Tomemos, por exemplo, São Paulo, que aparece em primeiro lugar tanto na análise das UFs como na análise das mesorregiões (metropolitana de São Paulo). Apesar desse excelente desempenho, o Estado de São Paulo contém três das suas 15 mesorregiões associadas a índices negativos, isto é, que apresentam desempenho menor que a média nacional. Assim como ocorre nesse Estado, diferenças significativas de desempenho nas 
7 Nesta análise, foi excluído o Distrito Federal, ao qual, por ser uma unidade com apenas uma região, não se aplica o estudo de heterogeneidade. Estão incluídas as demais 26 Unidades da Federação.

8 Na medida em que os índices foram construídos de tal forma que possuem média zero e desvio padrão unitário, escolhemos o próprio desvio padrão para medir o grau de heterogeneidade das mesorregiões no interior de cada Estado. mesorregiões estão presentes em muitas outras UFs. A Tabela $8^{7}$ apresenta algumas estatísticas que auxiliarão na análise das diferenças das mesorregiões. A tabela está ordenada pelo desvio padrão dos índices no interior de cada UF, isto é, em ordem decrescente de heterogeneidade. ${ }^{8}$ $\mathrm{Na}$ última coluna à direita, estão os valores dos índices calculados na seção 3.3. A inclusão desses dados possibilitará a análise conjunta de desempenho e heterogeneidade nas Unidades da Federação.

Para todas as UFs, os valores mínimos observados são sempre negativos, indicando que em todas elas existe ao menos uma região com desempenho menor que a média nacional. Comparando-se a heterogeneidade com o desempenho, observa-se que os oito maiores valores para o desvio padrão coincidem com oito dos nove Estados com índices positivos. Isto é, os melhores são os que apresentam a maior dispersão interna (a exceção é o Estado de Santa Catarina, que apresenta bom desempenho e baixa dispersão interna). A Tabela 9 mostra os índices das mesorregiões nesses Estados.

A regra, como se pode ver, é a presença de altos valores ao lado de valores bastante baixos numa mesma Unidade da Federação. O Rio de Janeiro, por exemplo, inclui três mesorregiões com índices iguais a 3,15 (2 ${ }^{\text {a }}$ colocada), 2,34 (4 ${ }^{\mathrm{a}}$ colocada) e $1,49\left(12^{\mathrm{a}}\right.$ colocada) e todas as demais mesorregiões com índices negativos. Chamam a atenção também os casos de Minas Gerais, Bahia, Paraná e Amazonas, que, embora tenham bom desempenho como Estados, apresentam mais da metade das suas mesorregiões com índices abaixo da média nacional.

Considerando todas as 26 Unidades da Federação analisadas, o desempenho e a heterogeneidade estão fortemente associados positivamente, conforme se verifica pelo coeficiente de correlação entre o índice de cada UF e o seu grau de heterogeneidade (desvio padrão) igual a 0,861.

Para fornecer uma visualização da associação das duas variáveis, foi montado o Quadro 1, que descreve a classificação de todas as Unidades da Federação no que se refere ao seu nível de desenvolvimento e ao seu grau de heterogeneidade. Foram considerados três níveis de desenvolvimento: alto com as nove melhores, médio com as nove seguintes, e baixo com as demais oito UFs. A heterogeneidade também foi classificada em três níveis, sendo:

- alta, se o desvio padrão for $>1,0$

(3 UFs);

- média, se 1,0 > desvio padrão > 0,5

(9 UFs);

- baixa, se o desvio padrão for $<0,5$ (14 UFs). 
Tabela 8_ Estatísticas para o índice dentro de cada UF (ordenadas pelo desvio padrão)

\begin{tabular}{|c|c|c|c|c|c|}
\hline UF & $\begin{array}{c}\mathbf{N}^{0} \text { de } \\
\text { Mesorregióes }\end{array}$ & Mínimo & Máximo & $\begin{array}{l}\text { Desvio } \\
\text { padrão }\end{array}$ & $\begin{array}{l}\text { Índice } \\
\text { (UF) }\end{array}$ \\
\hline $\mathrm{SP}$ & 15 & $-0,075$ & 6,356 & 1,664 & 3,302 \\
\hline RJ & 6 & $-0,389$ & 3,149 & 1,515 & 1,611 \\
\hline $\mathrm{AM}$ & 4 & $-1,422$ & 1,632 & 1,414 & 1,377 \\
\hline $\mathrm{ES}$ & 4 & $-0,491$ & 1,324 & 0,864 & 0,429 \\
\hline RS & 7 & $-0,388$ & 1,876 & 0,832 & 0,733 \\
\hline $\mathrm{BA}$ & 7 & $-0,782$ & 1,567 & 0,801 & 0,477 \\
\hline MG & 12 & $-0,955$ & 1,840 & 0,771 & 0,809 \\
\hline $\mathrm{PR}$ & 10 & $-0,584$ & 1,769 & 0,710 & 0,546 \\
\hline $\mathrm{PE}$ & 5 & $-1,260$ & 0,526 & 0,702 & $-0,474$ \\
\hline PA & 6 & $-1,539$ & 0,295 & 0,680 & $-0,609$ \\
\hline SE & 3 & $-0,956$ & 0,123 & 0,617 & $-0,200$ \\
\hline MA & 5 & $-0,970$ & 0,313 & 0,521 & $-0,521$ \\
\hline $\mathrm{PB}$ & 4 & $-1,403$ & $-0,412$ & 0,465 & $-0,741$ \\
\hline $\mathrm{SC}$ & 6 & $-0,274$ & 1,062 & 0,464 & 0,516 \\
\hline $\mathrm{CE}$ & 7 & $-0,945$ & 0,401 & 0,444 & $-0,438$ \\
\hline $\mathrm{AL}$ & 3 & $-1,147$ & $-0,286$ & 0,431 & $-1,479$ \\
\hline $\mathrm{AC}$ & 2 & $-1,290$ & $-0,759$ & 0,375 & $-1,029$ \\
\hline PI & 4 & $-0,698$ & 0,106 & 0,374 & $-0,649$ \\
\hline GO & 5 & $-0,394$ & 0,449 & 0,373 & $-0,155$ \\
\hline $\mathrm{RN}$ & 4 & $-0,708$ & 0,087 & 0,357 & $-0,404$ \\
\hline $\mathrm{RR}$ & 2 & $-0,486$ & $-0,042$ & 0,314 & $-0,672$ \\
\hline MT & 5 & $-0,568$ & 0,072 & 0,245 & $-0,472$ \\
\hline MS & 4 & $-0,417$ & $-0,099$ & 0,167 & $-0,513$ \\
\hline $\mathrm{RO}$ & 2 & $-0,625$ & $-0,413$ & 0,150 & $-0,872$ \\
\hline TO & 2 & $-0,617$ & $-0,460$ & 0,111 & $-0,840$ \\
\hline $\mathrm{AP}$ & 2. & $-0,200$. & $-0,197$. & $0,002$. & $-0,364$. \\
\hline
\end{tabular}

Fonte: Processamento dos autores a partir dos dados da RAIS 2004. 
Tabela 9_As 8 UFs mais heterogêneas, suas mesorregiões e seus índices

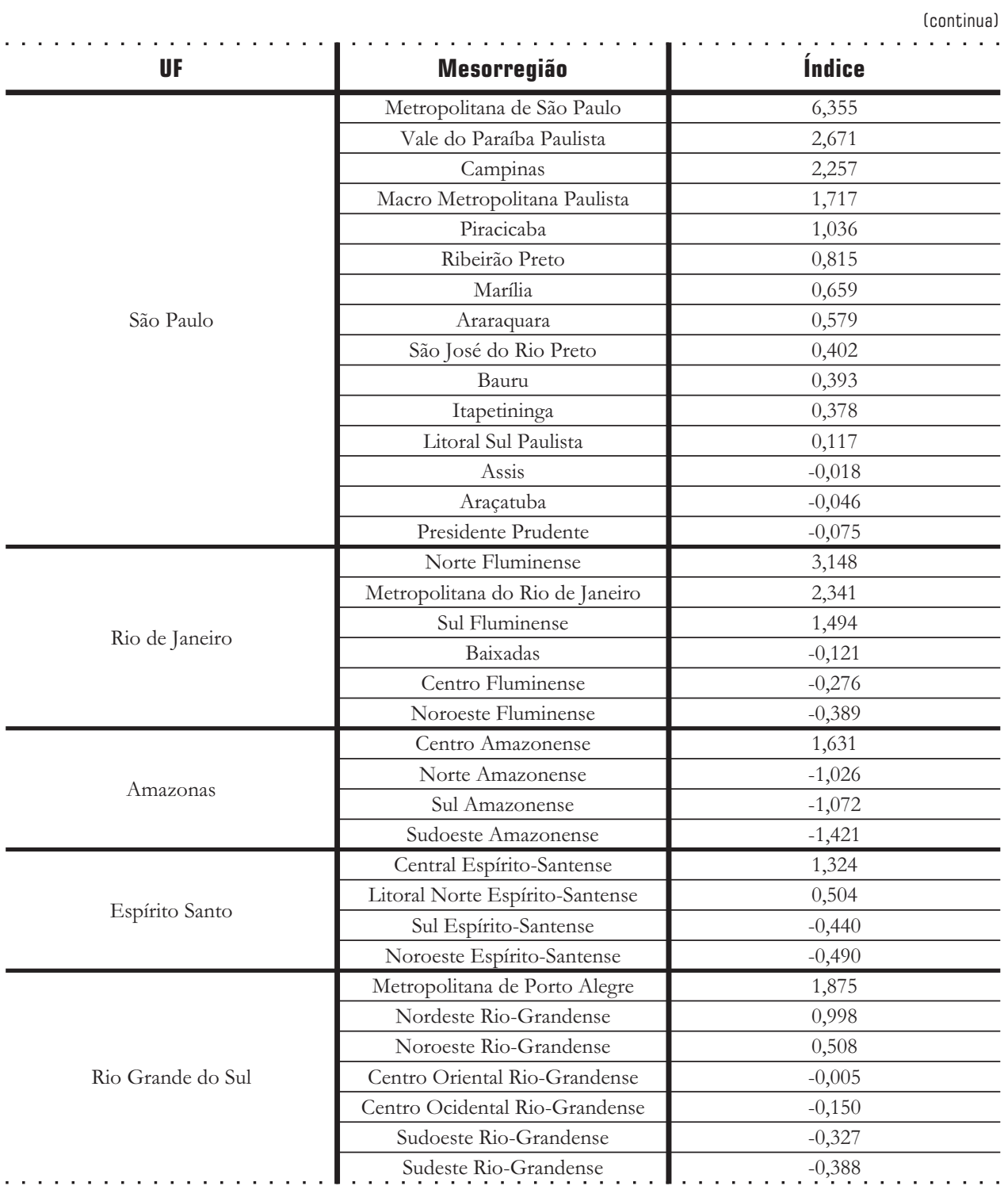


Tabela 9_As 8 UFs mais heterogêneas, suas mesorregiões e seus índices

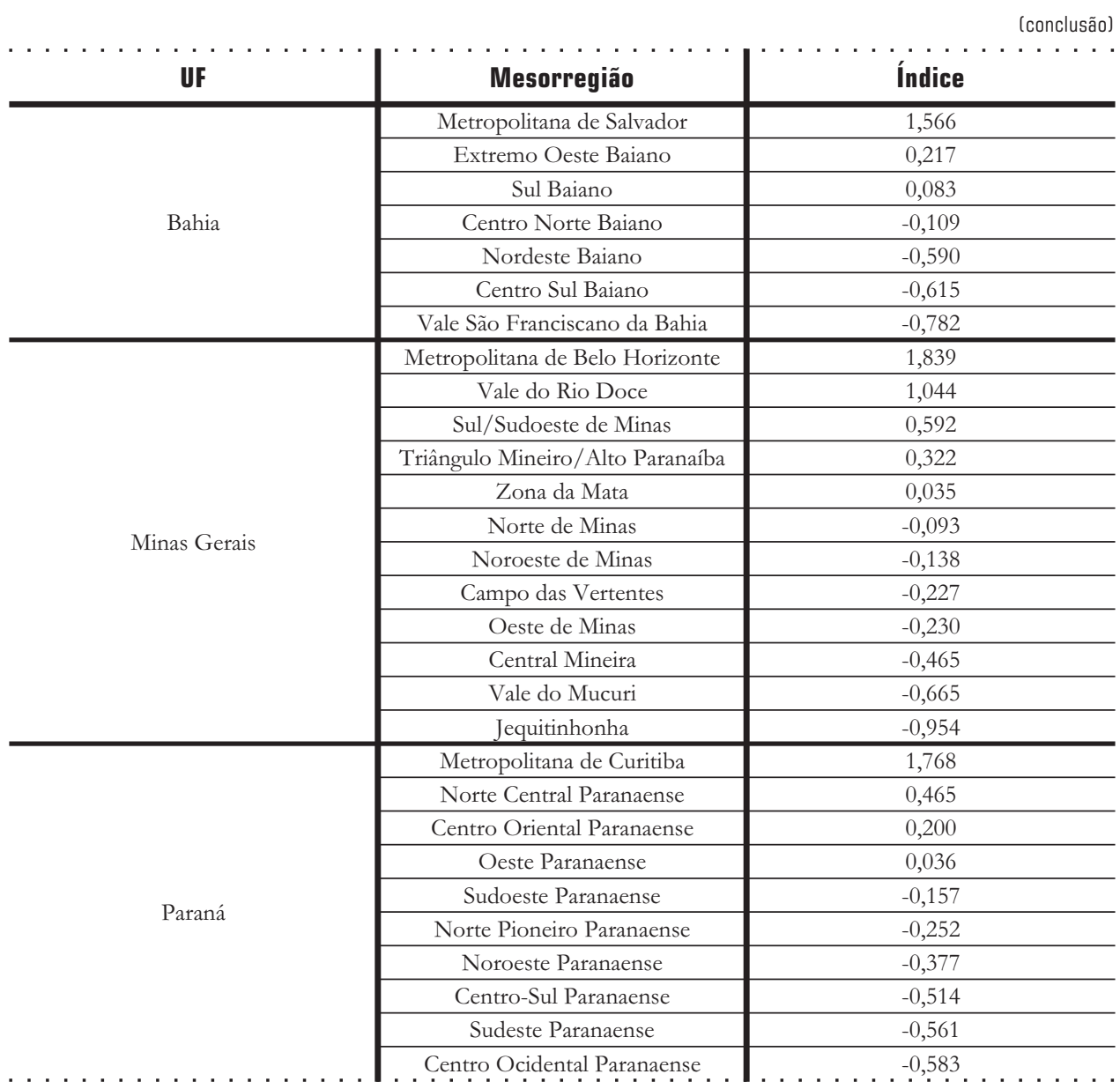

Fonte: Processamento dos autores a partir da tabela do Anexo. 
Quadro 1_Associação entre nível de desenvolvimento e grau de heterogeneidade nas UFs

\begin{tabular}{|c|c|c|c|}
\hline \multirow{2}{*}{$\begin{array}{c}\text { Nível de } \\
\text { Desenvolvimento }\end{array}$} & \multicolumn{3}{|c|}{ Heterogeneidade } \\
\hline & Alta & Média & Ваіка \\
\hline Alto & $\begin{array}{c}\text { São Paulo } \\
\text { Rio de Janeiro } \\
\text { Amazonas }\end{array}$ & $\begin{array}{c}\text { Espírito Santo } \\
\text { Rio Grande do Sul } \\
\text { Bahia } \\
\text { Minas Gerais } \\
\text { Paraná }\end{array}$ & Santa Catarina \\
\hline Médio & & $\begin{array}{l}\text { Pernambuco } \\
\text { Sergipe } \\
\text { Maranhão }\end{array}$ & $\begin{array}{c}\text { Goiás } \\
\text { Rio Grande do Norte } \\
\text { Mato Grosso } \\
\text { Mato Grosso do Sul } \\
\text { Amapá } \\
\text { Ceará }\end{array}$ \\
\hline Baixo & & Pará & $\begin{array}{c}\text { Acre } \\
\text { Piauí } \\
\text { Paraíba } \\
\text { Roraima } \\
\text { Rondônia } \\
\text { Tocantins } \\
\text { Alagoas }\end{array}$ \\
\hline
\end{tabular}

Fonte: Processamento dos autores a partir dos dados da RAIS 2004.

Como comentado anteriormente, das UFs classificadas com alto nível de desenvolvimento, apenas uma é classificada com baixa heterogeneidade (Santa Catarina). Por outro lado, considerando as oito UFs classificadas com baixo desenvolvimento, sete delas apresentam baixa heterogeneidade, $\mathrm{e}$ apenas uma apresenta média heterogeneidade (Pará). Os três Estados que apresentam alta heterogeneidade (São Paulo, Rio de Janeiro e Amazonas) são os que mostram os maiores valores para o índice. $\mathrm{O}$ nível médio de heterogeneidade é observado nos demais Estados da região Sudeste, quase todos da região Sul (exceto Santa Catarina), quatro da região Nordeste (Bahia, Pernambuco, Sergipe e Maranhão) e um da região Norte (Pará). A baixa heterogeneidade é característica do todos os Estados da região Centro-Oeste, cinco da região 
Nordeste (Rio Grande do Norte, Ceará, Piauí, Paraíba e Alagoas) e cinco da região Norte (Amapá, Acre, Roraima, Rondônia e Tocantins). Confirma-se, portanto, a forte associação positiva entre o nível de desenvolvimento e o grau de heterogeneidade no interior das UFs.

\section{5_Conclusão}

Neste trabalho, apresentamos uma análise regional da indústria de transformação e extrativa mineral baseada em cinco importantes indicadores. São eles o número de empregos, o número de estabelecimentos, o nível de remuneração, o nível de escolaridade e o percentual de profissionais técnicos e científicos na indústria local. A metodologia utilizada, baseada nas técnicas de Análise de Componentes Principais (ACP) e de Análise de Grupamento (AG), mostrou-se eficaz para descrever, diferenciar, ordenar e agrupar as Unidades da Federação e as mesorregiões, segundo o critério definido pelos cinco indicadores escolhidos.

No estudo das UFs, um resultado até certo ponto surpreendente foi encontrado no Estado do Amazonas, que apresentou valores máximos para a escolaridade dos trabalhadores e para o percentual de profissionais técnicos e científicos e que, junto com o valor relativamente alto apresentado para o nível de remuneração, garantiu a esse Estado o terceiro lugar na ordenação das Unidades da Federação. Alguns resultados já eram esperados, como o destaque para São Paulo e a melhor performance para os Estados das regiões Sudeste e Sul. Fora destas duas regiões e do Amazonas, apenas o Distrito Federal e a Bahia se destacaram. Os demais Estados apresentaram índices abaixo da média do País.

Em outras palavras, apenas três UFs fora do eixo Sul-Sudeste conseguiram se juntar às mais desenvolvidas do País. O Estado do Amazonas é um caso à parte, na medida em que é beneficiado pelo simples fato de abrigar a Zona Franca de Manaus. O Distrito Federal também representa uma situação especial, pois, embora tenha uma indústria de dimensão relativamente reduzida, apresenta bons indicadores por abrigar a capital do Brasil. A Bahia é o único Estado do Nordeste que apresenta, simultaneamente, uma indústria de dimensão razoável e, ao mesmo tempo, indicadores de remuneração, de escolaridade e de profissionais técnicos e científicos relativamente favoráveis.

A análise das 137 mesorregiões mostra com maior detalhe as diferenças regionais. Conforme esperado, a RM de São Paulo é o destaque positivo, apresentando indicadores bem mais favoráveis que as demais, resultando no índice mais elevado entre to- 
das as mesorregiões, especialmente pela dimensão de sua indústria. Ela é tão diferenciada das demais que foi excluída da Análise de Grupamento desenvolvida no trabalho.

As outras 50 mesorregiões que obtiveram Índice de Desenvolvimento Industrial positivo foram analisadas em dois grupos.

O primeiro grupo foi composto pelas 19 mesorregiões com os melhores valores do índice. Apenas três estão fora do eixo Sul-Sudeste, uma em cada uma das três Unidades da Federação apontadas acima: o Distrito Federal, o Centro Amazonense e a RM de Salvador. Entre as demais, cinco localizam-se em São Paulo, três no Rio de Janeiro, duas em Minas Gerais, Rio Grande do Sul e Santa Catarina e uma no Paraná e no Espírito Santo. Tal grupo pode ser desmembrado em dois subgrupos. O primeiro representa mesorregiões de maior dimensão industrial, porém com indicadores de remuneração, escolaridade e trabalhadores técnicos e científicos menos favoráveis. No segundo, são encontradas mesorregiões menores, todavia com indicadores mais favoráveis de qualidade do mercado de trabalho.

O segundo grupo englobou as outras 31 mesorregiões com índices positivos, isto é, acima da média, espalhadas por todo o País. Apesar disso, apenas 14 estão localizadas fora das regiões Sul e Sudeste, mais uma vez apontando para a concentração da indústria mais desenvolvida no Sul-Sudeste do País. Dessas, três estão em Goiás, duas no Pará e na Bahia, e uma no Ceará, Pernambuco, Rio Grande do Norte, Sergipe, Maranhão, Piauí e Mato Grosso. Em alguns casos, são regiões metropolitanas como Fortaleza, Recife e Belém ou mesorregiões no entorno das capitais. Em outros, o desenvolvimento industrial está associado ao deslocamento regional da agroindústria, como no Oeste Baiano. Enfim, as razões para o desenvolvimento dessas regiões fora do Sul-Sudeste são variadas e merecem ser aprofundadas.

As 86 mesorregiões restantes possuem índices negativos e estão majoritariamente localizadas nas regiões Norte, Nordeste e Centro-Oeste. Entre as 39 com os piores índices, apenas duas localizam-se fora dessas três regiões, ambas em Minas Gerais - Jequitinhonha e Vale do Mucuri.

Um dos resultados mais interessantes encontrados no trabalho foi a associação positiva entre o nível de desenvolvimento das UFs e o seu grau de heterogeneidade interna. Em outras palavras, são os Estados mais desenvolvidos do País que apresentam maior heterogeneidade entre suas mesorregiões e vice-versa. Tal resultado confirma a necessidade de desagregação espacial para a análise e o entendimento do que se passa no "interior" da indústria brasileira. 
Os resultados do artigo confirmam a continuidade da concentração industrial no Sul-Sudeste. Além de concentrada nessas duas regiões, sua "qualidade" é nitidamente superior. Apesar disso, a Análise de Grupamento e de componentes principais permitiu identificar várias mesorregiões no interior das regiões Norte, Nordeste e Centro-Oeste, que já conseguiram avançar razoavelmente, não somente em termos de volume de empregos e estabelecimentos industriais, mas também na qualidade dos empregos gerados.

A seqüência natural deste artigo é um aprofundamento do estudo das características setoriais da indústria local, no sentido de melhor compreensão dos elementos que caracterizam a estrutura industrial nas distintas localidades analisadas e das causas que resultam no desenvolvimento diferenciado da indústria nas várias regiões do País e no interior das Unidades da Federação. 


\section{Referências bibliográficas}

ANDRADE, T. A.; SERRA, R.

V. Distribuição espacial da indústria: possibilidades atuais para sua investigação. Estudos Econômicos, v. 30, n. 2, abr./jun. 2000.

AZEVEDO, P. F., TONETO JÚNIOR, R. Relocalização do emprego industrial formal no Brasil na década de 90. Pesquisa e Planejamento Econômico, v. 31, n. 1, abr. 2001.

BARROS, A. C. Relações intersetoriais em matrizes de insumo-produto: uma abordagem da Análise de Grupamento. 1992. Dissertação (Mestrado em Engenharia de Produção) Universidade Federal do Rio de Janeiro, Rio de Janeiro, 1992.

BRASIL. Ministério do Trabalho e Emprego. Departamento de Emprego e Salários. Bases Estatísticas. Relação Anual de Informações Sociais (Rais). Brasília, 2004.

CANO, W. Raízes da concentração industrial em São Paulo. São Paulo: DIFEL, 1977.
CANO, W. Desequilíbrios regionais e concentração industrial no Brasil. São Paulo: Global, 1985.

DE NEGRI, A.; SALERNO, M. S. (Orgs.). Inovações, padrões tecnológicos e desempenho das firmas industriais brasileiras. Brasília: IPEA, 2005.

DINIZ, C. C. Desenvolvimento poligonal no Brasil: nem desconcentração, nem contínua polarização. Nova Economia, Belo Horizonte, v. 3, n. 1, set. 1993.

DINIZ, C. C.; CROCCO, M. A. Reestruturação econômica e impacto regional: o novo mapa da indústria brasileira. Nova Economia, Belo Horizonte, v. 6, n. 1, jul. 1996.

GARCIA, R. A.; LEMOS, M. B.; CARVALHO, J. A. M.

A evolução das áreas de influência

demográfica e econômico-demográfica dos pólos econômicos brasileiros entre 1980 , 1991 e 2000. Belo Horizonte: Cedeplar, out. 2003. (Texto para Discussão, 224).

JOHNSON, R. A.; WICHERN, D. W. Applied Multivariate Statistical Analysis. New Jersey: Prentice-Hall, Inc., 1992.
KUBRUSLY, L. S. Um procedimento para calcular índices a partir de uma base de dados multivariados. Revista de Pesquisa Operacional, v. 21, n. 1, jun. 2001.

\section{KUPFER, D.; ROCHA, C.}

Dinâmica da produtividade $e$ heterogeneidade estrutural na indústria brasileira. Seminario El Reto de Acelerar el Crecimiento en América Latina y el Caribe. Santiago de Chile: CEPAL, 2004.

LEMOS, M. B. et al. A nova configuração regional brasileira e sua geografia econômica. Estudos Econômicos, v. 33, n. 4, out./dez. 2003.

LEMOS, M. B. et al. A organização territorial da indústria no Brasil. In: DE NEGRI, A.; SALERNO, M. S. (Orgs.). Inovações, padrões tecnológicos e desempenho das firmas industriais brasileiras. Brasília: IPEA, 2005.
PACHECO, C. A. Novos padrões de localização industrial? Tendências recentes dos indicadores $\mathrm{da}$ produção e do investimento industrial. Brasília: IPEA, mar. 1999. (Texto para Discussão, 633).

PEREIRA, F. M.; LEMOS, M. B. Cidades médias brasileiras: características e dinâmicas urbano-industriais. Pesquisa e Planejamento Econômico, v. 33, n. 1, abr. 2003.

RAMOS, L.; FERREIRA, V. Geração de empregos e realocação espacial do mercado de trabalho brasileiro - 1992-2002.

Pesquisa e Planejamento Econômico, v. 35, n. 1, abr. 2005.

SABOIA, J. Descentralização industrial no Brasil nos anos 90: um enfoque regional. Pesquisa e Planejamento Econômico, v. 30, n. 1, abr. 2000 .

SABOIA, J. Descentralização industrial no Brasil na década de noventa: um processo dinâmico e diferenciado regionalmente. Nova Economia, Belo Horizonte, v. 11, n. 2, dez. 2001. 
SABOIA, J. A indústria brasileira no Nordeste e as desigualdades inter e intra-regionais. Econômica, v. 6, n. 1, jun. 2004.

SABOIA, J.; KUBRUSLY, L.

Diferenciais regionais e setoriais na indústria brasileira. Economia Aplicada, v. 12, n. 1, jan./mar. 2008.

SPSS V 14. User's Guide, SPSS Inc, 2005.

SUZIGAN, W.; FURTADO, J.; GARCIA, R.; SAMPAIO, S. E.

$\mathrm{K}$. Aglomerações industriais no Estado de São Paulo. Economia Aplicada, v. 5, n. 4, out./dez. 2001.

\footnotetext{
Os autores agradecem a Fabio

- Roitman, Julia Torracca, Laura

- Beraldo e Renata Alvim pelo - processamento e pela organização. - dos dados utilizados neste - trabalho. Agradecem ainda as : criticas e sugestões feitas por um - parecerista anônimo à primeira - versão do artigo. $O$ artigo conton - com o apoio do CNPq.

E-mail de contato dos autores:

- saboia@superig.com.br

- amircb@hotmail.com

. luciak@alternex.com.br

.

- Artigo recebido em janeiro de 2007;

- aprovado em julho de 2008.
} 
Anexo

\section{Mesorregiões ordenadas pelo Índice (ACP)}

\begin{tabular}{|c|c|c|c|c|c|c|c|}
\hline UF & Mesorregiões & $\begin{array}{c}\text { Remuneração } \\
\text { (R\$) }\end{array}$ & $\begin{array}{l}\text { Escolaridade } \\
\text { (Anos) }\end{array}$ & $\begin{array}{l}\text { Técnicos } \\
\text { (\%) }\end{array}$ & $\begin{array}{c}\mathrm{N}^{\circ} \text { de } \\
\text { empregados }\end{array}$ & $\begin{array}{c}\mathrm{N}^{\circ} \text { de } \\
\text { estabele- } \\
\text { cimentos }\end{array}$ & $\begin{array}{l}\text { Icontinu } \\
\text { Índice }\end{array}$ \\
\hline SP & Metropolitana de São Paulo & 1.610 & 9,4 & 15,3 & 969.558 & 38.446 & 6,36 \\
\hline $\mathrm{RJ}$ & Norte Fluminense & 3.201 & 9,5 & 23,9 & 27.393 & 748 & 3,15 \\
\hline SP & Vale do Paraíba Paulista & 2.276 & 10,3 & 19,5 & 103.920 & 2.326 & 2,67 \\
\hline $\mathrm{RJ}$ & Metropolitana do Rio de Janeiro & 1.409 & 9,1 & 15,0 & 226.858 & 10.254 & 2,34 \\
\hline $\mathrm{SP}$ & Campinas & 1.438 & 9,3 & 13,0 & 249.478 & 9.134 & 2,26 \\
\hline RS & Metropolitana de Porto Alegre & 975 & 8,1 & 8,8 & 312.681 & 14.066 & 1,88 \\
\hline MG & Metropolitana de $\mathrm{BH}$ & 1.062 & 8,7 & 12,3 & 225.450 & 10.407 & 1,84 \\
\hline PR & Metropolitana de Curitiba & 1.199 & 9,4 & 13,3 & 161.527 & 7.434 & 1,77 \\
\hline SP & Macro Metropolitana Paulista & 1.312 & 9,2 & 13,5 & 174.966 & 5.241 & 1,72 \\
\hline $\mathrm{AM}$ & Centro Amazonense & 1.146 & 10,5 & 17,4 & 85.764 & 1.272 & 1,63 \\
\hline BA & Metropolitana de Salvador & 1.470 & 9,6 & 14,6 & 69.374 & 2.810 & 1,57 \\
\hline $\mathrm{RJ}$ & Sul Fluminense & 1.524 & 9,4 & 17,0 & 36.358 & 891 & 1,49 \\
\hline ES & Central Espírito-Santense & 1.153 & 9,5 & 16,0 & 48.670 & 2.631 & 1,32 \\
\hline $\mathrm{SC}$ & Norte Catarinense & 1.003 & 8,9 & 9,9 & 133.372 & 4.555 & 1,06 \\
\hline MG & Vale do Rio Doce & 1.238 & 8,9 & 14,0 & 36.306 & 1.851 & 1,04 \\
\hline SP & Piracicaba & 1.169 & 8,8 & 9,4 & 109.445 & 4.188 & 1,04 \\
\hline RS & Nordeste Rio-Grandense & 959 & 8,7 & 8,0 & 132.415 & 6.846 & 1,00 \\
\hline $\mathrm{SC}$ & Vale do Itajaí & 762 & 8,1 & 7,7 & 144.903 & 8.191 & 0,83 \\
\hline $\mathrm{SP}$ & Ribeirão Preto & 909 & 8,0 & 9,1 & 133.012 & 5.680 & 0,82 \\
\hline DF & Distrito Federal & 976 & 9,2 & 13,2 & 18.588 & 1.588 & 0,80 \\
\hline SP & Marília & 944 & 9,4 & 11,1 & 20.909 & 935 & 0,66 \\
\hline MG & Sul/Sudoeste de Mina & 686 & 8,2 & 8,1 & 103.044 & 6.392 & 0,59 \\
\hline SP & Araraquara & 1.059 & 8,8 & 8,2 & 53.518 & 1.968 & 0,58 \\
\hline PE & Metropolitana de Recife & 805 & 8,1 & 9,9 & 78.045 & 3.434 & 0,53 \\
\hline RS & Noroeste Rio-Grandense & 714 & 8,5 . & $7,8$. & 75.258. & 5.250 & $0,51$. \\
\hline
\end{tabular}




\section{Mesorregióes ordenadas pelo Índice (ACP)}

\begin{tabular}{|c|c|c|c|c|c|c|c|}
\hline UF & Mesorregióes & $\begin{array}{c}\text { Remuneração } \\
\text { (R\$) }\end{array}$ & $\begin{array}{c}\text { Escolaridade } \\
\text { (Anos) }\end{array}$ & $\begin{array}{l}\text { Técnicos } \\
\text { (\%) }\end{array}$ & $\begin{array}{c}N^{\circ} \text { de } \\
\text { empregados }\end{array}$ & $\begin{array}{l}\mathrm{N}^{\circ} \text { de } \\
\text { estabeleci- } \\
\text { mentos }\end{array}$ & Índice \\
\hline ES & Litoral Norte Espírito-Santense & 1.039 & 8,6 & 10,5 & 15.017 & 721 & 0,50 \\
\hline PR & Norte Central Paranaense & 633 & 8,5 & 5,5 & 112.214 & 6.234 & 0,47 \\
\hline $\mathrm{SC}$ & Grande Florianópolis & 761 & 9,0 & 9,4 & 27.691 & 2.473 & 0,45 \\
\hline $\mathrm{GO}$ & Centro Goiano & 586 & 8,4 & 6,9 & 87.969 & 6.313 & 0,45 \\
\hline SP & São José do Rio Preto & 759 & 8,6 & 7,6 & 60.813 & 3.579 & 0,40 \\
\hline $\mathrm{CE}$ & Metropolitana de Fortaleza & 530 & 8,4 & 7,2 & 115.817 & 4.771 & 0,40 \\
\hline SP & Bauru & 844 & 8,5 & 6,8 & 77.154 & 2.905 & 0,39 \\
\hline SP & Itapetininga & 861 & 8,5 & 9,9 & 32.303 & 1.233 & 0,38 \\
\hline $\mathrm{SC}$ & Sul Catarinense & 684 & 8,2 & 7,3 & 67.581 & 4.382 & 0,33 \\
\hline MG & Triângulo Mineiro/Alto Paranaíba & 762 & 8,0 & 7,5 & 71.189 & 3.720 & 0,32 \\
\hline $\mathrm{SC}$ & Oeste Catarinense & 667 & 8,2 & 7,1 & 89.796 & 3.886 & 0,31 \\
\hline MA & Norte Maranhense & 632 & 9,1 & 11,0 & 7.432 & 621 & 0,31 \\
\hline GO & Norte Goiano & 992 & 8,4 & 9,8 & 4.019 & 183 & 0,31 \\
\hline PA & Baixo Amazonas & 1.009 & 8,1 & 10,1 & 6.049 & 263 & 0,30 \\
\hline $\mathrm{BA}$ & Extremo Oeste Baiano & 641 & 8,2 & 12,9 & 1.800 & 187 & 0,22 \\
\hline PR & Centro Oriental Paranaense & 873 & 8,4 & 7,2 & 36.308 & 1.234 & 0,20 \\
\hline SE & Leste Sergipano & 926 & 7,5 & 8,8 & 25.212 & 1.013 & 0,12 \\
\hline SP & Litoral Sul Paulista & 898 & 8,4 & 7,9 & 3.198 & 323 & 0,12 \\
\hline PI & Sudoeste Piauiense & 380 & 8,5 & 13,4 & 982 & 104 & 0,11 \\
\hline GO & Sul Goiano & 721 & 8,2 & 8,0 & 33.353 & 1.436 & 0,10 \\
\hline $\mathrm{RN}$ & Oeste Potiguar & 974 & 7,5 & 8,6 & 11.479 & 591 & 0,09 \\
\hline $\mathrm{BA}$ & Sul Baiano & 683 & 7,8 & 10,1 & 17.404 & 1.239 & 0,08 \\
\hline MT & Centro-Sul Mato-Grossense & 666 & 8,7 & 7,3 & 18.799 & 1.144 & 0,07 \\
\hline PA & Metropolitana de Belém & 747 & 8,2 & 7,1 & 34.529 & 1.204 & 0,07 \\
\hline $\mathrm{PR}$ & Oeste Paranaense & 571 & 8,5 & 5,8 & 47.489 & 2.556 & 0,04 \\
\hline MG & Zona da Mata & 560 & 7,6 & 5,8 & 67.445 & 4.665 & 0,04 \\
\hline RS & Centro Oriental Rio-Grandense & 712 & 7,9 & 5,0 & 61.622 & 2.599 & $-0,01$ \\
\hline SP. & Assis. & 702 & 8,3 & 6,8 & 17.847 & 959 & $-0,02$. \\
\hline
\end{tabular}




\section{Mesorregióes ordenadas pelo Índice (ACP)}

\begin{tabular}{|c|c|c|c|c|c|c|c|}
\hline UF & Mesorregiões & $\begin{array}{c}\text { Remuneração } \\
\text { (R\$) }\end{array}$ & $\begin{array}{l}\text { Escolaridade } \\
\text { (Anos) }\end{array}$ & $\begin{array}{l}\text { Técnicos } \\
\text { (\%) }\end{array}$ & $\begin{array}{c}\mathbf{N}^{\circ} \text { de } \\
\text { empregados }\end{array}$ & $\begin{array}{l}N^{\circ} \text { de } \\
\text { estabeleci- } \\
\text { mentos }\end{array}$ & Icontinua \\
\hline $\mathrm{RR}$ & Sul de Roraima & 378 & 7,2 & 15,6 & 154 & 16 & $-0,04$ \\
\hline SP & Araçatuba & 627 & 8,5 & 5,1 & 42.726 & 1.600 & $-0,05$ \\
\hline MT & Nordeste Mato-Grossense & 572 & 6,8 & 14,0 & 3.762 & 221 & $-0,05$ \\
\hline MT & Sudeste Mato-Grossense & 747 & 8,1 & 7,2 & 6.820 & 527 & $-0,07$ \\
\hline SP & Presidente Prudente & 687 & 8,2 & 5,6 & 29.678 & 1.337 & $-0,08$ \\
\hline MG & Norte de Minas & 582 & 7,9 & 8,0 & 22.992 & 1.097 & $-0,09$ \\
\hline MS & Pantanais Sul Mato-Grossense & 838 & 7,9 & 6,9 & 2.353 & 146 & $-0,10$ \\
\hline $\mathrm{BA}$ & Centro Norte Baiano & 571 & 8,5 & 5,9 & 24.333 & 1.312 & $-0,11$ \\
\hline $\mathrm{RJ}$ & Baixadas & 855 & 7,3 & 7,9 & 4.259 & 420 & $-0,12$ \\
\hline MS & Centro Norte de MS & 631 & 8,1 & 7,1 & 15.915 & 850 & $-0,12$ \\
\hline MT & Sudoeste Mato-Grossense & 702 & 6,9 & 10,6 & 11.063 & 347 & $-0,14$ \\
\hline MG & Noroeste de Minas & 825 & 7,5 & 7,4 & 6.701 & 363 & $-0,14$ \\
\hline RS & Centro Ocidental Rio-Grandense & 618 & 8,1 & 7,0 & 10.688 & 921 & $-0,15$ \\
\hline $\mathrm{PR}$ & Sudoeste Paranaense & 523 & 8,7 & 5,1 & 21.556 & 1.294 & $-0,16$ \\
\hline $\mathrm{RN}$ & Leste Potiguar & 594 & 7,8 & 6,4 & 35.478 & 1.234 & $-0,16$ \\
\hline $\mathrm{AP}$ & Norte do Amapá & 667 & 6,3 & 12,6 & 159 & 6 & $-0,20$ \\
\hline $\mathrm{AP}$ & Sul do Amapá & 735 & 7,8 & 6,6 & 2.620 & 225 & $-0,20$ \\
\hline MA & Leste Maranhense & 711 & 7,4 & 7,8 & 3.958 & 161 & $-0,23$ \\
\hline MG & Campo das Vertentes & 645 & 7,8 & 6,1 & 14.483 & 1.083 & $-0,23$ \\
\hline MG & Oeste de Minas & 517 & 7,3 & 4,0 & 61.648 & 4.168 & $-0,23$ \\
\hline PR & Norte Pioneiro Paranaense & 593 & 8,1 & 5,3 & 18.242 & 913 & $-0,25$ \\
\hline $\mathrm{SC}$ & Serrana & 713 & 7,6 & 5,0 & 19.588 & 1.062 & $-0,27$ \\
\hline $\mathrm{RJ}$ & Centro Fluminense & 599 & 7,5 & 6,0 & 22.307 & 1.398 & $-0,28$ \\
\hline $\mathrm{AL}$ & Sertão Alagoano & 580 & 7,3 & 8,9 & 762 & 43 & $-0,29$ \\
\hline $\mathrm{GO}$ & Leste Goiano & 610 & 8,0 & 5,4 & 6.897 & 556 & $-0,31$ \\
\hline RS & Sudoeste Rio-Grandense & 668 & 8,2 & 3,7 & 8.032 & 636 & $-0,33$ \\
\hline PI & Centro-Norte Piauiense & 434 & 7,7 & 7,0 & 16.313 & 1.064 & $-0,33$ \\
\hline $\mathrm{PE}$ & S. Francisco Pernambucano & 562. & $8,3$. & 4,9 . & 2.569 . & 229. & $-0,34$ \\
\hline
\end{tabular}




\section{Mesorregióes ordenadas pelo Índice (ACP)}

\begin{tabular}{|c|c|c|c|c|c|c|c|}
\hline UF & Mesorregióes & $\begin{array}{c}\text { Remuneração } \\
\text { (R\$) }\end{array}$ & $\begin{array}{c}\text { Escolaridade } \\
\text { (Anos) }\end{array}$ & $\begin{array}{l}\text { Técnicos } \\
\text { (\%) }\end{array}$ & $\begin{array}{c}N^{\circ} \text { de } \\
\text { empregados }\end{array}$ & $\begin{array}{c}N^{\circ} \text { de } \\
\text { estabeleci- } \\
\text { mentos }\end{array}$ & Índice \\
\hline PR & Noroeste Paranaense & 495 & 7,7 & 3,6 & 38.780 & 2.114 & $-0,38$ \\
\hline MS & Sudoeste de MS & 559 & 7,6 & 5,5 & 17.308 & 815 & $-0,38$ \\
\hline RS & Sudeste Rio-Grandense & 670 & 7,0 & 5,7 & 18.982 & 1.125 & $-0,39$ \\
\hline RJ & Noroeste Fluminense & 524 & 7,4 & 6,9 & 6.282 & 622 & $-0,39$ \\
\hline $\mathrm{GO}$ & Noroeste Goiano & 700 & 7,8 & 4,3 & 3.340 & 138 & $-0,39$ \\
\hline $\mathrm{PB}$ & Agreste Paraibano & 458 & 7,6 & 6,1 & 16.849 & 902 & $-0,41$ \\
\hline $\mathrm{RO}$ & Madeira-Guaporé & 531 & 7,7 & 5,7 & 5.917 & 502 & $-0,41$ \\
\hline MS & Leste de MS & 576 & 7,7 & 4,7 & 12.815 & 616 & $-0,42$ \\
\hline $\mathrm{PB}$ & Mata Paraibana & 529 & 7,1 & 6,0 & 29.515 & 974 & $-0,43$ \\
\hline ES & Sul Espírito-Santense & 615 & 7,4 & 3,8 & 16.427 & 1.321 & $-0,44$ \\
\hline $\mathrm{TO}$ & Oriental do Tocantins & 515 & 7,8 & 5,2 & 2.653 & 289 & $-0,46$ \\
\hline MG & Central Mineira & 572 & 7,4 & 4,7 & 13.169 & 898 & $-0,47$ \\
\hline $\mathrm{RR}$ & Norte de Roraima & 481 & 7,8 & 5,4 & 1.369 & 154 & $-0,49$ \\
\hline ES & Noroeste Espírito-Santense & 452 & 7,9 & 3,8 & 17.050 & 1.048 & $-0,49$ \\
\hline $\mathrm{PR}$ & Centro-Sul Paranaense & 602 & 7,0 & 4,4 & 18.159 & 959 & $-0,51$ \\
\hline $\mathrm{RN}$ & Central Potiguar & 685 & 6,7 & 5,4 & 5.944 & 417 & $-0,52$ \\
\hline PR & Sudeste Paranaense & 619 & 7,0 & 3,6 & 18.399 & 1.117 & $-0,56$ \\
\hline MT & Norte Mato-Grossense & 599 & 6,7 & 3,2 & 31.086 & 2.036 & $-0,57$ \\
\hline PR & Centro Ocidental Paranaense & 492 & 7,8 & 2,8 & 9.585 & 562 & $-0,58$ \\
\hline $\mathrm{BA}$ & Nordeste Baiano & 438 & 7,5 & 4,7 & 8.124 & 431 & $-0,59$ \\
\hline PE & Agreste Pernambucano & 409 & 7,3 & 3,8 & 19.157 & 1.799 & $-0,60$ \\
\hline $\mathrm{CE}$ & Sul Cearense & 376 & 7,8 & 3,8 & 12.339 & 682 & $-0,60$ \\
\hline $\mathrm{BA}$ & Centro Sul Baiano & 441 & 7,3 & 3,5 & 21.588 & 1.285 & $-0,62$ \\
\hline $\mathrm{TO}$ & Ocidental do Tocantins & 457 & 7,6 & 3,6 & 6.049 & 486 & $-0,62$ \\
\hline $\mathrm{RO}$ & Leste Rondoniense & 488 & 6,8 & 4,3 & 20.028 & 1.329 & $-0,62$ \\
\hline $\mathrm{CE}$ & Noroeste Cearense & 430 & 7,7 & 2,8 & 22.545 & 410 & $-0,63$ \\
\hline CE & Sertões Cearenses & 391 & 7,1 & 5,7 & 1.531 & 183 & $-0,66$ \\
\hline PI. & Sudeste Piauiense. & 491. & $6,6$. & 6,4 & 1.384 & 110. & $-0,66$. \\
\hline
\end{tabular}




\section{Mesorregióes ordenadas pelo Índice (ACP)}

\begin{tabular}{|c|c|c|c|c|c|c|c|}
\hline UF & Mesorregiões & $\begin{array}{c}\text { Remuneração } \\
\text { (R\$) }\end{array}$ & $\begin{array}{l}\text { Escolaridade } \\
\text { (Anos) }\end{array}$ & $\begin{array}{c}\text { Técnicos } \\
\text { (\%) }\end{array}$ & $\begin{array}{c}\mathbf{N}^{\circ} \text { de } \\
\text { empregados }\end{array}$ & $\begin{array}{l}\mathrm{N}^{\circ} \text { de } \\
\text { estabeleci- } \\
\text { mentos }\end{array}$ & conclusão \\
\hline MG & Vale do Mucuri & 475 & 7,0 & 4,9 & 3.023 & 284 & $-0,67$ \\
\hline $\mathrm{AL}$ & Agreste Alagoano & 437 & 7,0 & 5,0 & 3.479 & 188 & $-0,69$ \\
\hline PI & Norte Piauiense & 388 & 7,3 & 4,7 & 2.098 & 236 & $-0,70$ \\
\hline $\mathrm{CE}$ & Norte Cearense & 438 & 7,4 & 3,1 & 13.519 & 302 & $-0,70$ \\
\hline $\mathrm{RN}$ & Agreste Potiguar & 326 & 8,4 & 1,6 & 2.194 & 104 & $-0,71$ \\
\hline MA & Oeste Maranhense & 531 & 6,5 & 4,5 & 8.990 & 497 & $-0,73$ \\
\hline PA & Nordeste Paraense & 536 & 5,3 & 8,0 & 9.087 & 339 & $-0,75$ \\
\hline $\mathrm{AC}$ & Vale do Acre & 490 & 6,4 & 5,2 & 3.330 & 296 & $-0,76$ \\
\hline MA & Sul Maranhense & 490 & 6,6 & 4,5 & 1.292 & 78 & $-0,78$ \\
\hline BA & Vale São-Franciscano & 552 & 6,3 & 4,4 & 4.376 & 231 & $-0,78$ \\
\hline PA & Sudeste Paraense & 602 & 5,1 & 5,4 & 31.502 & 1.074 & $-0,80$ \\
\hline $\mathrm{PB}$ & Sertão Paraibano & 328 & 7,2 & 3,4 & 3.656 & 388 & $-0,82$ \\
\hline $\mathrm{CE}$ & Jaguaribe & 380 & 6,9 & 3,3 & 8.691 & 338 & $-0,84$ \\
\hline SE & Sertão Sergipano & 348 & 6,9 & 2,8 & 500 & 49 & $-0,93$ \\
\hline $\mathrm{CE}$ & Centro-Sul Cearense & 335 & 7,1 & 2,0 & 2.412 & 185 & $-0,94$ \\
\hline $\mathrm{PA}$ & Sudoeste Paraense & 538 & 6,2 & 2,3 & 4.897 & 302 & $-0,95$ \\
\hline MG & Jequitinhonha & 481 & 6,1 & 3,2 & 3.871 & 407 & $-0,95$ \\
\hline SE & Agreste Sergipano & 353 & 6,4 & 3,6 & 3.404 & 278 & $-0,96$ \\
\hline MA & Centro Maranhense & 397 & 6,4 & 3,4 & 1.518 & 120 & $-0,97$ \\
\hline $\mathrm{AM}$ & Norte Amazonense & 641 & 6,3 & 0,0 & 6 & 3 & $-1,03$ \\
\hline $\mathrm{PE}$ & Sertão Pernambucano & 379 & 5,9 & 3,0 & 4.313 & 477 & $-1,06$ \\
\hline $\mathrm{AM}$ & Sul Amazonense & 416 & 6,6 & 1,0 & 390 & 23 & $-1,07$ \\
\hline $\mathrm{AL}$ & Leste Alagoano & 524 & 3,5 & 4,0 & 86.464 & 924 & $-1,15$ \\
\hline $\mathrm{PE}$ & Mata Pernambucana & 498 & 4,0 & 2,9 & 43.125 & 608 & $-1,26$ \\
\hline $\mathrm{AC}$ & Vale do Juruá & 308 & 5,9 & 1,0 & 314 & 57 & $-1,29$ \\
\hline $\mathrm{PB}$ & Borborema & 369 & 5,1 & 1,1 & 1.133 & 120 & $-1,40$ \\
\hline $\mathrm{AM}$ & Sudoeste Amazonense & 417 & 4,8 & 1,3 & 76 & 6 & $-1,42$ \\
\hline PA & Marajó & 478. & $3,8$. & 1,7 & 4.415 & 60. & $-1,54$. \\
\hline
\end{tabular}

Fonte: Processamento dos autores a partir dos dados da RAIS 2004. 